\title{
Investigation of seasonal thermal flow in a real dam reservoir using 3-D numerical modeling
}

\author{
Fatih Üneş ${ }^{*}$, Hakan Varçin \\ Mustafa Kemal University, Engineering Faculty, Civil Engineering Department, Hydraulics Division, 31200, Iskenderun, Hatay, Turkey. \\ *Corresponding author. E-mails: funes@mku.edu.tr, fatihunes66@gmail.com
}

\begin{abstract}
Investigations indicate that correct estimation of seasonal thermal stratification in a dam reservoir is very important for the dam reservoir water quality modeling and water management problems. The main aim of this study is to develop a hydrodynamics model of an actual dam reservoir in three dimensions for simulating a real dam reservoir flows for different seasons. The model is developed using nonlinear and unsteady continuity, momentum, energy and k- $\varepsilon$ turbulence model equations. In order to include the Coriolis force effect on the flow in a dam reservoir, Coriolis force parameter is also added the model equations. Those equations are constructed using actual dimensions, shape, boundary and initial conditions of the dam and reservoir. Temperature profiles and flow visualizations are used to evaluate flow conditions in the reservoir. Reservoir flow's process and parameters are determined all over the reservoir. The mathematical model developed is capable of simulating the flow and thermal characteristics of the reservoir system for seasonal heat exchanges. Model simulations results obtained are compared with field measurements obtained from gauging stations for flows in different seasons. The results show a good agreement with the field measurements.
\end{abstract}

Keywords: Real dam reservoir; Thermal stratification; Mathematical model; Density flow; Divergence flow.

\section{INTRODUCTION}

Previous studies evaluate reservoirs as stratified or unstratified reservoirs either using density currents caused by density (cooling water) or lightly (warming water) buoyant flows entering dam reservoir by reviewing many different fields of engineering such as hydraulics, limnology, meteorology and geophysics. These flows can be aroused from different densities due to temperature, chemicals, concentration of dissolved or suspended substances or a combination of both. The variations in densities affect the gravity that causes the actual driving force of flows. As river flow enters ambient dam reservoir water, three basic types of currents can occur, namely the overflow; interflow, and plunging (density, negatively buoyant) flow. If density of incoming flow is smaller than ambient water body in the reservoir, this type of flow will move along the free surface and is called overflow. If reservoir ambient water is stratified due to temperature or other effects, incoming flow will go forward at an intermediate layer whose density will be equal to inflow density. This flow is called interflow. However, if river water flowing into ambient dam reservoir water is higher than quiescent water density of reservoir, then this type of flow will plunge below the ambient water and will move along the reservoir bottom. This flow is named underflow, density negatively flows or plunging flow (Alavian et al., 1992; Farrell and Stefan, 1988; Üneş, 2008a, b).

Due to varieties in temperatures across the seasons, river flows entering into the dam reservoir can have different temperatures and therefore different densities. These variations may lead to lateral mixing of the inflow and uncertain currents in dam reservoir. Moreover, real dam reservoirs can have very variable cross section geometry, shape and volume. Therefore, seasonal temperatures and the geometry of dam reservoir can play an important role in the formation of flow in the reservoir (such as buoyancy flow, overflow, interflow, plunging or density flow, and divergence flows such as wall jet flow, separated flow of the wall, attached flow and free jet flow).
Density currents in lakes and reservoirs have been observed in fields by many researchers (Alavian and Ostrowski, 1992; Fischer and Smith, 1983; Ford et al., 1983; Hebbert et al., 1979). Many researchers have treated the stratified reservoir, density plunging and divergence flow released on a sloping bottom in laboratory conditions (Akiyama and Stefan, 1984; Alavian, 1986; Choi and Garcia, 2002; Chung and Gu, 1998; Dallimore et al., 2004; Hauenstein and Dracos, 1984; Parker et al., 1987; Savage and Brimberg, 1975; Singh and Shah 1971). Some of them have established a number of semi empirical equations. Although most of the data available are from flume tests in laboratory, such experimental work is not sufficient to understand the longitudinal developments of the hydraulic characteristics of density flows over a long distance. On the other hand, mathematical models can give more information about density flow characteristics over the entire dam reservoir. Therefore a few authors have also considered the problem by solving it using mathematical models and numerical solution to investigate the plunging and underflow (Bournet et al., 1999; Farrell and Stefan, 1986, 1988; Fukushima and Watanabe, 1990; Üneş 2004, 2005, 2010; Üneş and Ağıralioğlu, 2004). In the numerical approach, plunge region need not be isolated from the rest of the reservoir so that the river inflow can be simulated along the reservoir. In this solution, plunge region will appear in the emerging flow field as a part of the overall solution. Such a solution has provided useful results for further realistic reservoir model studies.

Various extraneous forces or factors such as wind, waves, dissolved or suspended materials etc. can exert an influence on the plunging flow dynamics. All forces can be expected to take effect in a real reservoir flow. The mentioned possible effects or factors are omitted in the present study in order to facilitate the solution, even though they may have some effects over the reservoir flow. In order to facilitate the model solution, the free surface of the reservoir is modeled as a rigid lid during the present model simulation (Farrell and Stefan 1986, 1988; Ünes 2008a, b, 2010). In this manner reservoir level variation and the 
free surface phenomena such as wind or wave effects are not being considered in reservoir model.

Another simplification in the model is that the temperature difference is taken to be the source of the stratified and buoyancy flows. Since turbidity current occurring due to sediment laden reduces dam storage capacity, turbidity current and carrying sediment laden also can be an important parameter. Numerous researches related to density current were carried out both experimentally and theoretically by Stefan (1973), Garcia (1993, 1994), Bradford et al. (1997), Lee and Yu (1997), Yu et al. (2000), Kostic and Parker (2003, 2006), Wright and Parker (2004), Violet et al. (2005), Lamb et al. (2004, 2006), De Cesare et al. (2006), Hassan et al. (2006) and Toniolo et al. (2006). However, at present, new master projects include many consecutive dam constructions. In such dams, one dam outflow creates inflow in another dam (see Fig.1). For this reason, the important issue in this type of project is to construct an accurate thermal stratification flow. It can be seen from field and experimental works that small temperature differences are enough to produce density flow in the reservoir (Farrell and Stefan, 1986). Therefore, the density-temperature relation is taken as the source of the stratified and buoyancy flows.

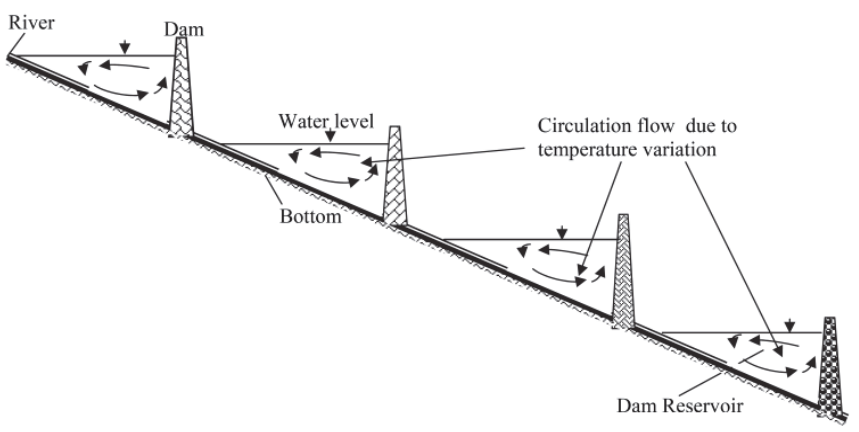

Fig. 1. Schematic figure of consecutive dams.

Currently, few researchers used three dimension model simulations and experimental studies to understand the influence of flow inlet condition, density variation and the divergence angle into dam reservoir (Johnson and Stefan, 1988; Johnson et al., 1987a, b; Kassem et al., 2003; Üneş, 2008a, b). Plunging flows in the field could be dramatically different from those in laboratory modeling. In practice, variation in flow along the reservoir and the variations in depth and time make the measurements difficult, laborious and even impossible in some parts such as dam outflows.

In the present paper, a simulation model of a real reservoir of medium size is investigated using a previously developed numerical model of the dynamics of a dam reservoir in three dimensions (3-D) by Üneş (2008b, 2009, 2010). Since this type of study requires an accurate description of the dynamics of inflow rivers and dam properties, the dominant physical processes, initial and boundary conditions in the long run variation such as seasonal temperatures, inlet discharge and reservoir level are incorporated in the simulation model. Therefore, a detailed field study and measurements are necessary in order to obtain reliable inflow parameters, initial and boundary conditions.

The main aim of this research is to create a dam reservoir model as accurate as possible to define realistic dam reservoir flow parameters. In this way, the effect of the wall divergence angle in reservoir inlet, channel bottom slope variation of flow types and parameters through the dam reservoir can be investigated. In this paper, results of such detailed 3-D model and simulations are used to determine reservoir flow and parameters such as plunging point, thermal and velocity variation through the Eğrekkaya dam reservoir of Ankara, Turkey. In a similar manner, model accuracy are also evaluated and compared with those indicated by the field data measurements from Eğrekkaya dam reservoir gauging stations.

\section{PRESENT STUDY}

Reservoir geometry, various forces or factors such as wind, waves, sediment load of river, industrial outlets to reservoir and the temperature effects caused by meteorological inputs etc. can exert an influence on the plunging flow dynamics. The forces and factors can effect to move the plunge point and plunge line. The above mentioned factors such as wind, waves, sediment are omitted in the present model in order to facilitate the solution, even though they may have some effects over the reservoir flow. The temperature variation effects caused by meteorological inputs are considered of initial condition of model in this study.

Three dimensional mathematical model is used to better understand the real dam reservoir flow. The present model equations are solved using FLUENT computational fluid dynamics software program based on the initial and boundary conditions of the field measurement reservoir flow parameters. Model equations are solved using control-volume-based technique. If dam reservoir with large-volume and long-dimensions (width and length on the surface of Eğrekkaya reservoir in July, respectively, $2360 \mathrm{~m}$ and $7800 \mathrm{~m}$ ) is considered as a whole, the Coriolis force effect should be added in the model. In this respect, if real reservoir conditions want to be obtained, the dam reservoir is investigated by using the mathematical model including Coriolis force. However, since the software does not incorporate Coriolis effect, a user defined function is written in the $\mathrm{C}$ language to take into account this effect in the software program.

In the model simulations, it is assumed that density flows occur only due to differences in temperatures of ambient water and inflow water. These flow types are modeled for different seasonal conditions. The model can simulate the entire very long-dimensions reservoir, and unlike previous studies, plunging region and other parts of dam reservoir need not be separated from entire reservoir flow.

Stratified flows such as plunging and overflow and seasonal variation are examined using temperature variation through three-dimensions in a real dam reservoir. The flow parameters are evaluated from temperature contour and desired velocity vector profiles in reservoir. Since density dam reservoir flows include inverse and circulation flow properties, the existing model use eddy viscosities to describe vertical transport due to velocity at the interface on stratified or density flow. To calculate eddy viscosities, k- $\varepsilon$ turbulence model approach is used (Choi and Garcia, 2002; Farrell and Stefan, 1986, 1988). This method is very useful for the complex reservoirs that have inner circulation and temperature stratified flows. Since the density difference occurs due to varying water temperatures, the present mathematical model includes an energy equation for the heat transport in the reservoir (Üneş, 2008a, b).

\section{THE MATHEMATICAL MODEL DESCRIPTION}

The reservoir shape is given in Fig. 2, and is located in three dimensional, $x, y$ and $z$, Cartesian coordinates. Since hydrodynamic modeling of dam reservoir contains many parameters, it is a very complicated phenomenon and hard to solve. Therefore, some simplification process has to be made before presenting the governing equations. One of them, the free surface phenomenon such as wind or wave effect is not being considered in re- 


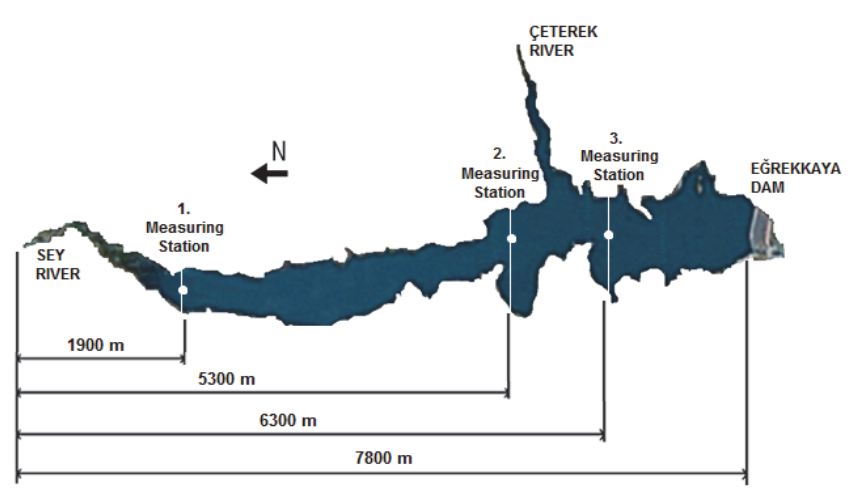

Fig. 2. Eğrekkaya reservoir (Goggle Earth) and measuring stations (Üneş, 2009).

servoir surface, and the free surface of the reservoir is modeled as rigid lid in the present model simulation. Furthermore, suspended or dissolved substances effects are neglected on density differences. Another simplification is that the temperature difference is taken to be the source of the stratified and buoyancy flow. Inflow river properties, such as temperature variations and turbidity currents exhibit different models of density currents. It is a fact that turbidity current occurring due to sediment laden reduces dam storage capacity. Since, at present, a new master project includes consecutive dam construction and one dam outflow creates inflow in another dam (see Fig. 1), the most effective parameter is taken as temperature change of density reservoir flow.

From field and practice, small temperature differences are enough to produce density flow in the reservoir, Farrell and Stefan (1986). Therefore, the density-term in the momentum equation can be linearized using the following approximation:

$$
\rho=\Delta \rho+\rho_{0}=\beta \rho_{0}\left[T_{0}-T\right]
$$

where $\rho$ is the water density, $T$ is the water temperature and $\beta$ is the coefficient of thermal expansion and is calculated as $\beta=$ $-\left(\Delta \rho / \rho_{\mathrm{o}}\right)(1 / \Delta T)$, where $\Delta T$ is the temperature difference between ambient and inflow river waters, $\rho_{o}$ and $T_{o}$ refer to the reservoir conditions. Equation (1) can be substituted into the momentum equation. If density variation is not large, " $\left(\Delta \rho / \rho_{o}\right)$ " is neglected part of multiplier in temporal and convective terms in the momentum equations, and this process is called "Boussinesq approximation". Reduced pressure approach, $P^{\prime}=P-\rho_{o} g y$, is also considered another simplification in this work. This relationship is meaningful only when the rigid lid assumption is used. The occurred deflection along dam reservoir flow due to Coriolis effects are considers in mathematical model for the northern hemisphere. The amount of deflection of flow particles is directly related to both its speed and latitude. The Coriolis effect is only applied in the $x$ and $y$ components of the momentum equations and energy equation. The Coriolis parameter, $f$, used in the mathematical model can be written as

$$
f=2 \Omega \sin \Theta
$$

where $\Omega$ is the earth angular velocity at a value of $7.29 \times 10^{-5} 1 / \mathrm{s}$ and $\Theta$ is the latitude of the investigated place, as described Pedlosky (1987).

If all the previous processes are applied, the mathematical model consists of the following equations: the continuity equation, momentum equations, energy equation and the turbulence model equations. When momentum equations are examined, it can be seen that reduced pressure and buoyancy terms, $\beta \rho_{0}\left[T_{0}-T\right]$ is directly related to the gravitation effect. Therefore one of the main driving forces is gravitational force effecting density flow in a dam reservoir (Üneş, 2008a, b).

Continuity equation

$$
\frac{\partial \rho}{\partial t}+\frac{\partial(\rho \bar{u})}{\partial x}+\frac{\partial(\rho \bar{v})}{\partial y}+\frac{\partial(\rho \bar{w})}{\partial z}=0
$$

\section{Momentum equations}

For the $x$ axis,

$$
\begin{aligned}
& \frac{\partial \bar{u}}{\partial t}+\bar{u} \frac{\partial \bar{u}}{\partial x}+\bar{v} \frac{\partial \bar{u}}{\partial y}-\bar{w} \frac{\partial \bar{u}}{\partial z}-f \bar{v}=-\frac{1}{\rho_{o}} \frac{\partial \bar{P}}{\partial x}+ \\
& v_{e f f}\left(\left(\frac{\partial^{2} \bar{u}}{\partial x^{2}}+\frac{\partial^{2} \bar{u}}{\partial y^{2}}+\frac{\partial^{2} \bar{u}}{\partial z^{2}}\right)+\left(\frac{\partial^{2} \bar{u}}{\partial x^{2}}+\frac{\partial^{2} \bar{v}}{\partial x \partial y}+\frac{\partial^{2} \bar{w}}{\partial x \partial z}\right)\right)
\end{aligned}
$$

for the $y$ axis,

$$
\begin{aligned}
& \frac{\partial \bar{v}}{\partial t}+\bar{u} \frac{\partial \bar{v}}{\partial x}+\bar{v} \frac{\partial \bar{v}}{\partial y}+\bar{w} \frac{\partial \bar{v}}{\partial z}+f \bar{u}= \\
& -\frac{1}{\rho_{o}} \frac{\partial \bar{P}}{\partial y}+v_{e f f}\left(\left(\frac{\partial^{2} \bar{v}}{\partial x^{2}}+\frac{\partial^{2} \bar{v}}{\partial y^{2}}+\frac{\partial^{2} \bar{v}}{\partial z^{2}}\right)+\left(\frac{\partial^{2} \bar{u}}{\partial y \partial x}+\frac{\partial^{2} \bar{v}}{\partial y^{2}}+\frac{\partial^{2} \bar{w}}{\partial y \partial z}\right)\right)
\end{aligned}
$$

and for the $z$ axis,

$\frac{\partial \bar{w}}{\partial t}+\frac{\partial \bar{w}}{\partial x}+v \frac{\partial \bar{w}}{\partial y}+\frac{\partial \bar{w}}{\partial z}=-\frac{1}{\rho_{o}} \frac{\partial \bar{P}}{\partial y}+$

$v_{e f f}\left(\left(\frac{\partial^{2} \bar{w}}{\partial x^{2}}+\frac{\partial^{2} \bar{w}}{\partial y^{2}}+\frac{\partial^{2} \bar{w}}{\partial z^{2}}\right)+\left(\frac{\partial^{2} \bar{u}}{\partial z \partial y}+\frac{\partial^{2} \bar{v}}{\partial z \partial y}+\frac{\partial^{2} \bar{w}}{\partial z^{2}}\right)\right)+g \beta\left(T_{o}-\bar{T}\right)$

\section{Energy equation}

Temperature field is defined by solving the following Energy equation

$$
\frac{\partial \bar{T}}{\partial t}+\bar{u} \frac{\partial \bar{T}}{\partial x}+\bar{v} \frac{\partial \bar{T}}{\partial y}+\bar{w} \frac{\partial \bar{T}}{\partial z}=\alpha_{e f f}\left(\frac{\partial^{2} \bar{T}}{\partial x^{2}}+\frac{\partial^{2} \bar{T}}{\partial y^{2}}+\frac{\partial^{2} \bar{T}}{\partial z^{2}}\right)
$$

where $\bar{u}$ and $\bar{v}$ are the mean velocities in the $x$ and $y$ directions, respectively, $\rho$ is the water density, $\bar{P}=\overline{P^{\prime}}+\rho k(2 / 3)$, $\overline{P^{\prime}}$ is the mean pressure adjusted to absorb the hydrostatic portion of the gravity terms, $k$ is turbulent kinetic energy and $\bar{T}$ is the mean temperature, $v_{\text {eff }}=v+v_{t}$, where $v$ is the kinematics viscosity and $v_{t}$ is the kinematics eddy (turbulence) viscosity; and $\alpha_{\text {eff }}=(v / P r)+\left(v_{t} / \sigma_{t}\right)$ is effective thermal diffusivity coefficient; where $\mathrm{Pr}$ and $\sigma_{t}$ are the Prandtl and turbulent Prandtl numbers, respectively.

\section{$k$ - $\varepsilon$ turbulence model equations}

Since density dam reservoir flows include inverse and circulation flow properties, the existing model uses eddy viscosities 
to describe vertical transport due to velocity at the interface on stratified or density flow. To calculate eddy viscosities, k- $-\varepsilon$ turbulence model approach is used Choi and Garcia (2002). This method is very useful for the complex reservoirs that have inner circulation and temperature stratified flows. The effect of turbulence is simulated using the modified standard k- $\varepsilon$ turbulence model including the suitable buoyancy terms. Standard k$\varepsilon$ model is a semi-empirical model of Launder and Spalding (1972) based on model transport equations for turbulent kinetic energy $(k)$ and its dissipation rate $(\varepsilon)$. $\mathrm{k}-\varepsilon$ transport model equations have been implemented by Rodi (1987).

For a three dimensional unsteady flow at the sloping bottom reservoir, the eddy viscosity $v_{t}$ is computed from the following equation,

$$
v_{t}=C_{\mu} \frac{k^{2}}{\varepsilon}
$$

where $k$ is the turbulent kinetic energy and $\varepsilon$ is the turbulent energy dissipation rate per unit mass. $k$ and $\varepsilon$ are obtained from the solution of the following equations in three-dimensional flow, Farrell and Stefan (1986).

Equation of $k$

$$
\frac{\partial k}{\partial t}+\bar{u}_{j} \frac{\partial k}{\partial x_{j}}=\frac{\partial}{\partial x_{j}}\left[\left(v+\frac{v_{t}}{\sigma_{k}}\right) \frac{\partial k}{\partial x_{j}}\right]+\operatorname{Prod}+G-\varepsilon
$$

and equation of $\varepsilon$,

$$
\begin{aligned}
& \rho \frac{\partial \varepsilon}{\partial t}+\bar{u}_{j} \frac{\partial \varepsilon}{\partial x_{j}}=\frac{\partial}{\partial x_{j}}\left[\left(v+\frac{v_{t}}{\sigma_{\varepsilon}}\right) \frac{\partial \varepsilon}{\partial x_{j}}\right]+ \\
& C_{1 \varepsilon} \frac{\varepsilon}{k} \operatorname{Prod}-C_{2 \varepsilon} \frac{\varepsilon^{2}}{k}+C_{1 \varepsilon} C_{3} \frac{\varepsilon}{k} G
\end{aligned}
$$

where Prod is the production of turbulent kinetic energy from the mean flow and is given as

$$
\operatorname{Prod}=v_{t}\left(\frac{\partial \bar{u}_{i}}{\partial x_{j}}+\frac{\partial \bar{u}_{j}}{\partial x_{i}}\right) \frac{\partial \bar{u}_{i}}{\partial x_{j}}
$$

In these equations, $G$ is the production or destruction of turbulent kinetic energy by buoyancy forces and is given as;

$$
G=g_{i} \beta \frac{v_{t}}{\sigma_{t}} \frac{\partial \bar{T}}{\partial x_{i}}
$$

where $\beta$ is thermal expansion coefficient. In addition, the values of the coefficients $C_{\mu}, C_{I \varepsilon}, C_{2 \varepsilon}, C_{3}, \sigma_{k}, \sigma_{3}$, and $\sigma_{t}$ appearing in the $\mathrm{k}-\varepsilon$ turbulence model equations used herein were given the standard values recommended by Launder and Spalding (1987). For the standard k- $\varepsilon$ model, these constants are taken as $C_{\mu}=$ $0.09, C_{l \varepsilon}=1.44, C_{2 \varepsilon}=1.92, \sigma_{k}=1.00, \sigma_{\varepsilon}=1.3$, and $\sigma_{t}=0.9 . C_{3}$ is not part of the standard k- $\varepsilon$ model but enter through the buoyancy terms and the constant $C_{3}$ is not a stable value. In FLUENT, $C_{3}$ is not specified, but is instead calculated according to $C_{3}=$ $\tanh |\mathrm{w} / \mathrm{u}|$, where $\mathrm{w}$ is the component of the flow velocity parallel to the gravitational vector and $u$ is the component of the flow velocity perpendicular to the gravitational vector. Further details and solution procedure can be found in the FLUENT user's guide (2008).

\section{Boundary and initial conditions}

Since reservoir density flow is unsteady and turbulence flow, boundary conditions in the flow field must be specified individually on the reservoir inlet and outlet planes, at the walls and at the free surface. Moreover, initial fields for each variable must also be specified. So for each variable, boundary and initial conditions must be chosen individually. This is treated as follows:

Velocity is given a symmetry condition at the free surface. At the reservoir bottom and dam face, velocities are determined using the standard wall function that is based on the proposal of Launder and Spalding (1974). This function assumes a log-law velocity profile near the wall and is provided in FLUENT as follows;

$$
\frac{u_{p}}{u_{*}}=\frac{1}{K} \ln \left(E \frac{u_{*} y_{p}}{v}\right)-\Delta B
$$

where $u_{p}$ is the mean flow velocity at point $p ; u_{*}$ is the friction velocity; $K$ is the von Karman constant; $E$ is the empirical constant having a value of $9.81 ; y_{p}$ is the distance from point $p$ to the wall; and $\Delta B$ s the roughness function that depends, in general, on the wall roughness height, Ks. At the inflow boundary, the horizontal velocity component in the $x$ direction, $u$, is given uniform velocity distribution. The vertical velocity component in the $y$ direction, $v$, is set to zero. At the outflow point of the reservoir, the horizontal velocity component is allocated a value in order to exactly balance inflow and the vertical velocity component is taken as zero. The initial velocity field into the reservoir consists of a forward horizontal velocity, $u$, and zero vertical velocity, $v$, at all points except close to dam.

The bottom and the free surface of the reservoir's temperatures are taken as adiabatic. The initial temperature field consists of a constant temperature throughout the reservoir. The dam face temperature is taken equal to the initial temperature of the reservoir water. The inflow river water temperature is set at a constant value with no variation over river depth. Reservoir temperature conditions were changed later during the simulation run time. Therefore, initial temperature values are not of importance.

The $k$ and $\varepsilon$ are given a symmetry condition at the free surface the same as the velocity condition in the turbulence model. So a zero gradient condition for $k$ is valid at the reservoir bottom and on the dam face. $k$ and $\varepsilon$ in the inflow river and near the wall grid points are given a linear profile related to the river shear velocity, $u *$ is proposed by Launder and Spalding (1972, 1974). At the outflow point, $k$ and $\varepsilon$ conditions are the same as the velocity conditions. That is, the zero gradient condition is imposed at the outflow point for $k$ and $\varepsilon$.

\section{Numerical method and application details}

The above governing equations are solved by using the computational fluid dynamics solver FLUENT. In the study, the program solves the governing integral equations for the conservation of mass and momentum, energy and turbulence equations using Pressure-based solver numerical method. In this approach, the pressure field is extracted by solving a pressure or pressure correction equation which is obtained from continuity and momentum equations. In the solution control-volume-based technique is used. This technique contains three steps. First, a division of the domain into discrete control volumes is made using a computational grid. Secondly, integration of the governing 
equations is performed on the individual control volumes to construct algebraic equations for the discrete dependent variables such as velocities, pressure, temperature, and turbulence parameters. Finally, linearization of the discretized equations and solution of the resultant linear equation system is updated values of the dependent variables.

When the velocity fields into the dam reservoir have complex currents such as density flow or circulation flow, two types of problems arise because of the density reservoir flow. These problems are nonlinearity and velocity-pressure field interdependent. These problems are solved using the SIMPLE procedure of Patankar and Spalding (1972). This procedure is the iteration method and is based on the prediction- corrector approach. FLUENT provides the option to choose SIMPLE pressure-velocity coupling algorithms. The fluxes through the control volume faces are computed using power law scheme of Patankar (1980). Since the density flow is unsteady and the run time is large due to reservoir dimensions, the fully implicit scheme is used for converting the discrete equations in the present model to give a stable and realistic solution for large time steps.

Numerical diffusion is one of the serious problems in computational fluid dynamics. Numerical diffusion arises because of the inability of a discrete grid in space and time to perfectly simulate continuous process (Farrell and Stefan, 1986). In the literature, there are many kinds of numerical diffusion, but in this study, skewness error is taken into account. If flows such as recirculation flow, plunging flow, and underflow in a dam reservoir take place with an angle to the numerical scheme grid lines, it is well known that the occurrence of skewness error is inevitable. The error can be defined in the mixing interface of the density stratified flow.

In this study, the tetrahedral-hybrid mesh shape is chosen in the model solution. The mesh qualities are controlled with equiangle skewness, equisize skewness and aspect ratio in drawing software. Skewness and other problems are solved taking smaller mesh dimension grid line. When the real shape of reservoir is considered in the model, the skewness error is increased due to a very intricate shape of the reservoir. Those errors were corrected by increasing the numbers of mesh. However, when the mesh gets smaller, the numbers of mesh are increased. Obviously, this requires more computer capacity and time.

\section{CASE STUDY}

Field data gathered from the Eğrekkaya dam reservoir is used to obtain flows that may occur through a real dam reservoir. Eğrekkaya Dam in Ankara region (capital of Turkey) was selected for this study. The dam was built for the drinking water supplies of Ankara and is $70 \mathrm{~km}$ away from Ankara. Eğrekkaya dam is an earth-fill dam; crest length is $340 \mathrm{~m}$, height from the river bed is $67 \mathrm{~m}$, drainage basin area is about $780 \mathrm{~km}^{2}$ and the maximum volume of reservoir is almost $113.0 \mathrm{hm}^{3}$. Eğrekkaya dam reservoir was observed in July and March. However, the highest inflow to dam reservoir was observed in March and April. Moreover, the most water consumption in reservoir occurred in April and August. In addition to, the most evaporation was observed in July and August.

The data for Eğrekkaya dam (used in this study) have been obtained from Turkish General Directorate of State Hydraulic Works (DSI). The observed (monitored) data comprises the time period between Feb. 1999 and Oct. 2000 on a monthly average basis DSI (2001). Three measurement stations are established by DSI for water quality modeling through the dam reservoir.
Eğrekkaya reservoir map has an intricate configuration due to narrow and variable cross-section (Fig. 2). The reservoir is $7.8 \mathrm{~km}$ long along the centerline and $2.36 \mathrm{~km}$ wide at the widest location observed in July. The Sey and Çeterek River flow into the reservoir. Three measuring stations on the dam reservoir are located on the reservoir centerline approximately $1.9 \mathrm{~km}$, $5.3 \mathrm{~km}$ and $6.3 \mathrm{~km}$ respectively from the reservoir inlet and presented in Fig. 2. Temperature variation data measured at three gauging station are shown Fig. 3. Inflow discharges from two inlet and monthly mean temperature variation data measured at inlet gauging station are presented in Table 1 . In the Table, $T_{s}\left({ }^{\circ} \mathrm{C}\right)$, the water temperature of entering Sey River; $T_{c}$ $\left({ }^{\circ} \mathrm{C}\right)$, the water temperature of entering Çeterek River; $T_{o}\left({ }^{\circ} \mathrm{C}\right)$, reservoir ambient water temperature; $Q_{s}$ and $Q_{c}\left(\mathrm{~m}^{3} / \mathrm{s}\right)$, monthly mean inflow discharges of Sey and Çeterek River. The measurement comparison data for temperature variation in reservoir were the major component of density difference between the inflow and dam reservoir during the period of interest (July and March). These monthly time periods are considered because they well represent the dam conditions such as plunging flow, overflow and the variation of dam dimensions during these seasons.

Table 1. Two river inflow data entering Eğrekkaya dam reservoir (DSI, 2001).

\begin{tabular}{ccccccc}
\hline & \multicolumn{3}{c}{ Sey River } & \multicolumn{3}{c}{ Çeterek River } \\
\cline { 2 - 7 } & $\begin{array}{c}T_{s} \\
\left({ }^{\circ} \mathrm{C}\right)\end{array}$ & $\begin{array}{c}T_{o} \\
\left({ }^{\circ} \mathrm{C}\right)\end{array}$ & $\begin{array}{c}Q_{s} \\
\left(\mathrm{~m}^{3} / \mathrm{s}\right)\end{array}$ & $\begin{array}{c}T_{c} \\
\left({ }^{\circ} \mathrm{C}\right)\end{array}$ & $\begin{array}{c}T_{o} \\
\left({ }^{\circ} \mathrm{C}\right)\end{array}$ & $\begin{array}{c}Q_{c} \\
\left(\mathrm{~m}^{3} / \mathrm{s}\right)\end{array}$ \\
\hline March & 4.3 & 4.4 & 6.4 & 3.6 & 4.4 & 2.5 \\
\hline July & 7.8 & 23.4 & 2.0 & 5.5 & 23.4 & 0.2 \\
\hline
\end{tabular}

The reservoir flows are stratified during the warm season due to temperature variations as seen in Fig. 3. These stratified flows occur as densities or plunging flow during the spring and summer season due to temperature variation between inflow and ambient water. Unlike the hot seasons, overflows can be observed in the winter season since the inflow and ambient water temperatures are almost equal. Therefore, vertical stratification is relatively stable during the winter. Fig. 3 shows that water temperatures in Eğrekkaya reservoir were in the range of $5-24^{\circ} \mathrm{C}$ in the July and approximately constant at $4^{\circ} \mathrm{C}$ in March. Table 1 shows that for the two rivers, Sey and Çeterek, flow discharges entering the reservoir were observed average 6.4 and $2.5 \mathrm{~m}^{3} / \mathrm{s}$, respectively, and ambient water temperature was defined $4.4^{\circ} \mathrm{C}$ in the March. However, flow discharges entering the reservoir in the July were observed 2.0 and $0.2 \mathrm{~m}^{3} / \mathrm{s}$, respectively, ambient water temperature was defined $23.4^{\circ} \mathrm{C}$.

\section{APPLICATION OF THE DAM RESERVOIR MODEL}

Before preparing the mathematical model of Eğrekkaya dam in FLUENT, a drawing software program, GAMBIT, is used to draw the experimental reservoir configuration. The reservoir shape is sketched with the drawing software by taking a crosssection of each $50-100 \mathrm{~m}$ along the reservoir $(67$ and $57 \mathrm{~m}$ in depth, 2360 and $1975 \mathrm{~m}$ in width, 7800 and $6900 \mathrm{~m}$ in length for warm and cold season, respectively) as given in Figs 4 and 5a. (DSI, 2001). The proposed mathematical model is implemented in FLUENT with the appropriate boundary and initial conditions. As can be seen in Fig. 4, two different plan-section and dimension were observed in the reservoir due to seasonal operating works throughout the year. Therefore, for the selected seasons, the reservoir water level, volume and shape vary. In winter, reservoir water level decreases to 10 meters due to res- 
ervoir operating policy and supply drinking water during the summer season.

The present model was used to simulate the seasonal variation of real dam reservoir flow. The biggest problem during the implementation of the real dam reservoir in FLUENT model is skewness error of network grid. In the literature, there are many kinds of numerical diffusion, but in this study, especially skewness error which is part of numerical diffusion is taken into account. If flows such as recirculation flow, plunging flow, and underflow in a dam reservoir take place with an angle to the numerical scheme grid lines, it is well known that the occurrence of skewness error is inevitable. The error can be defined in mixing interface of the density stratified flow, as shown in Fig. 5b. The Figure shows thermocline stratified flow mesh grid line. Herein, $\mathrm{u}$, w shows the presentation of the velocity component in the numerical scheme grid line. As can be seen from figure, information of point $\mathrm{B}$ is obtained from convection at points $\mathrm{A}$ and $\mathrm{C}$. While point $\mathrm{C}$ takes part in the warm circulation flow water, point $\mathrm{A}$ takes part in cold underflow water. This situation causes numerical diffusion in the numerical solution. Since the real shape of reservoir is considered in the model, the skewness error is increased due to a very intricate shape of the reservoir. These errors are examined and corrected by increasing the numbers of mesh. Furthermore, the computational domains for all cases are approximately divided 1070000 1010000 tetrahedral mesh volumes to obtain acceptable skewness coefficients, as seen in Fig. 5a. This represents approximately 2500000 nodes. In the model cases, the convergence criterion of flow parameters is taken 0.001 for all the runs.

High capacity parallel computer system, which has 16 processors, was used in the application of the model. Each process has 1 GB RAM, and high data store capacity. Since Eğrekkaya dam reservoir has big dimension and volume, iteration and solution time of simulation model took approximately 2 months per seasonal model simulation. The calculation and iterations continued until the change observed in the flow field was insignificant. The time is enough to see the underflow developing through the dam reservoir and any changes in the flow characteristic. In order to have the desired converged solution, a time step size of 50-100 seconds and maximum number of iterations per time step of 10 were chosen after the preliminary trials.

\section{MODEL RESULTS}

All seasonal simulations yielded realistic flows measured in the field. Ambient reservoir water and inflow river water temperature vary during the year. This change creates different types of density flow in the reservoir. Since the incoming flow temperature is generally lower than the ambient water body in the reservoir during the hot season, incoming flow moves along the bottom of the dam ambient water as underflow (density negatively flow or plunging flow). However, unlike the summer season, incoming river flow temperature is generally equal to or sometimes greater than the ambient water body in the reservoir during the winter. In this case, incoming river flow as over-flow will move along the free surface.

In the model application, the reservoir is first filled with warm water in accordance with the measured reservoir surface water temperature and air temperature, and then the cold water in accordance with the measured inflow rivers water temperatures and discharges are released at the upstream end of the inflow rivers channel at a specified rate. The current proceeds forward until it reaches the downstream boundary. The present model is the first step in the real dam reservoir simulation model. The entire reservoir flow can be simulated with presented model approach. Therefore, plunging region needs not be separated from entire reservoir flow as the previous study.

As expected from the typical model, initially the cold inflow river water advanced into the reservoir, and pushed forward under the quiescent warm water. Then the warm water is displaced forward and the flows are in the downstream direction at all points. The warm water is initially displaced forward. When the denser cold water pushed slightly forward under the warm water, consequently a small region of recirculation flow appeared on both the cross-section and the ambient water surface. In this way plunging flow started and then the river inflow coldwater flow downstream under the ambient warm water as a density current. Therefore, as inflow river water plunges, the ambient water is entrained in the downstream direction and underflow is diluted.

Flow parameters (temperature, velocity, pressure, etc.) are defined at every point of the reservoir in the simulation model. For representing spring and summer seasons, temperature stratified flow and plunging (density) flow are clearly obtained from the model in July. On the other hand, for representing winter seasons, overflow and stratified flow are obtained in March from the model. The model results were compared with the field reservoir measurements (for July and March months) obtained from DSI technical report about Eğrekkaya reservoir and basin pollution research DSI (2001). The model showed a good agreement with the field values for these stations. Then, the stratified flow, density, and speed and temperature variation in the reservoir body are obtained for whole dam reservoir. The results obtained simulations provide confirmation of models ability for real dam reservoir flow.

\section{Model results and evaluations for July (representing the Summer season flows)}

In order to examine the real dimension reservoir flow for the Summer season in this study, the mathematical model governing equations is solved and analyzed for July with the computational fluid dynamics solver FLUENT. The results obtained from model for July were also examined and compared with observed field data. The measurements for July showed that inflow water temperatures for Sey and Çeterek rivers, $T_{s}$ and $T_{c}$ were 7.8 and $5.5^{\circ} \mathrm{C}$, respectively (Table 1). In addition to river inflow temperature, the ambient water temperature was $23.4^{\circ} \mathrm{C}$. Therefore, the density stratified flows are formed due to the different warmth between stable water and inflow river water. The run simulations in July show that initially the inflow cold river water advanced into the dam reservoir, and pushed forward under the ambient warm water. Then the warm water is displaced forward and the flows are in the downstream direction at all points. The warm water is initially displaced forward. When the denser cold water pushed slightly forward under the warm water, recirculation region appeared on both the section and the ambient water surface. Then, plunging flow starts and consequently the river inflow cold water flows the downstream under the ambient warm water as underflow current. Together with these formations, since inflow river water plunges, ambient water is entrained in the downstream direction and underflow water is diluted due to entrainment from circulation warm water.

Temperature variations along the reservoir depth obtained from these simulations and the measurements of DSI (2001) are compared and the percentages of errors are shown in Fig. 6 and given in Table 2 . The percentages of errors at the $1^{\text {st }}, 2^{\text {nd }}$ and $3^{\text {rd }}$ gauging stations were $2.9,4.5$ and $3.8 \%$, respectively. The percentages of errors made in laboratory conditions in literature 
ranged from 15 to $25 \%$ (Farrell and Stefan, 1986; Singh and Shah, 1971; Üneş, 2008a). It can be seen from the data and results in Table 2 and Fig. 6 that the mathematical model and simulation results are found to be of the same magnitude as the field measurements in respective stations. These results indicate that the mathematical model can effectively be used for reservoir flow estimation.

Thermocline and velocity vectors variations are simulated for July conditions representing the summer season. Temperature variations of the model are consistent with the reservoir measurements. These cases are investigated at three field station cross-sections where observations are made, namely, $1.9 \mathrm{~km}$, $5.3 \mathrm{~km}$ and $6.3 \mathrm{~km}$ respectively along the reservoir. The contours at the surface and the longitudinal sections $(1.2 \mathrm{~km}$, $1.4 \mathrm{~km}, 1.6 \mathrm{~km}$, and $2.0 \mathrm{~km}$ respectively) are also investigated and evaluated. Figs. 7, 8, and 9 show contours of temperature fields of real dam reservoir for three measuring station crosssections and different longitudinal sections in 3-D. Thermocline variations in the reservoir are defined through the dam face, cross and longitudinal sections. Fig. 7 represents the 3-D plot of the thermocline variation obtained from the model for Station-1 and seven-sections along the Eğrekkaya dam reservoir. Fig. 8 shows the results of the thermocline variation obtained from the model for Station-2 and 3, and also for along the reservoir. Temperature variation along the reservoir, stratified, and development of underflow can be clearly seen in Fig. 8. In addition, Fig. 9 shows the dam model perspective view from the downstream, and the temperature variation for station-3, and also for the dam face.

Furthermore, Fig. 10 and 11 show the behavior of flow entrance of the Sey and Çeterek rivers and plunging points in the reservoir. As seen, the entering current of the Sey River becomes attached to one wall that is similar to the diffuser models previously reported in literature. Therefore, a typical attached wall jet flow forms at the reservoir entrance. Then, wall jet flow and separations appear only at the side wall of reservoir. In general, if diffuser half-divergence angles (convergence angle of reservoir inlet) of reservoir entrance are between $10^{\circ}$ to $40^{\circ}$, then the wall attached flow forms at the reservoir entrance (Johnson et al., 1987a, 1987b, 1988; Üneş, 2008a, 2008b). In these types of formations, separations from the one side wall of the reservoir appear which is named wall attached jet flow. Since Sey river's inlet divergence angles are small, the wall jet flow is formed in the simulation model. Together with stall formation and velocity variation, the wall jet flow can clearly be defined from the simulation figures.

In accordance with the previous studies, Sey and Çeterek rivers form the wall jet flow in the entrance of the reservoir. It should be noticed in Fig. 10 that if the entrance of the dam reservoir has a small divergence angle, the inflow river water becomes attached to one wall, wall jet flow, and then a stalled region will develop near the other wall. Further away from the entrance, the plunging flow occurs and under flow layer forms and then the ambient water uniformly moves to the upstream. The ambient water is entrained laterally by the wall jet in the plunge region. In such cases, the entrainment occurs near the water surface and through the recirculation stalled region.

Plunging point in the model is taken as the position where underflow reaches the dam. Sey and Çeterek River's plunging points are observed nearly $1750 \mathrm{~m}$ and $700 \mathrm{~m}$, respectively, as seen in simulation model results in Figs 10-11. The locations of plunging and the wall jet flow vary according to changing reservoir conditions (temperatures and discharges of inflow river, and changes in seasonal conditions, etc.), and flow hydrodynamics.
As it can be seen from the results of the model, the plunge location in entrance of Sey and Çeterek river affected the inlet condition, density and the divergence angle of the ambient water. Therefore, the plunge point, location and depth are never stabilized and plunge point continues to move back and forth based on the inflow water and environmental conditions of the dam. Density flow behavior in the model is developed in a similar manner as in the observation and laboratory model works.

Fig. 12 shows the plot of the thermocline contour sections, and variations on the side surface along the reservoir in July. As seen in these figures, temperature variations changes as the depths increase. Since Eğrekkaya reservoir map has an intricate configuration, the water temperature of the reservoir increases along the reservoir shoreline and secluded places due to shallow water at littoral zone. As expected, the water temperatures in shallow water along the shoreline are much higher than deepwater parts of the reservoir as seen in Fig. 12. The determination of the temperature variations in a dam reservoir is of importance particularly in terms of environmental pollution and water quality modeling.

\section{Model results and evaluations for March (representing the Winter seasons flow)}

The results obtained from model simulation in March were also examined and compared with observed field data from Eğrekkaya dam. Inflow water temperatures for Sey and Çeterek river, $T_{s}$ and $T_{c}$, as measured in March, were 4.3 and $3.6{ }^{\circ} \mathrm{C}$, respectively, as it can be seen in Table 1 . In addition to river inflow temperature, the ambient water temperature was $4.4^{\circ} \mathrm{C}$. Temperature variations along the reservoir depth obtained from these simulations and the measurements of DSI (2001) are compared and percentages of errors are given in Fig. 13 and Table 3. Percentages of errors of gauging stations 1,2 and 3 are determined as $0.9,3.4$ and $3.8 \%$, respectively. It can be seen from the data and results in Table 3 and Fig. 13 that the mathematical model and simulation results are found to be of the same magnitude as the field observations. The thermocline variations for March indicate that overflow, density flow, and recirculation zone development into the reservoir can be well defined in the temperature fields in the model simulation results, as seen Fig. 13.

Temperature contours, lines of constant temperature, are found for March conditions representing the winter season. The simulation and results are investigated at three measuring station cross-sections, namely, $1.9 \mathrm{~km}, 5.3 \mathrm{~km}$, and $6.3 \mathrm{~km}$, respectively along the reservoir. In addition to these, the temperature contours at the water surface and longitudinal section, namely, $1.2 \mathrm{~km}, 1.4 \mathrm{~km}, 1.6 \mathrm{~km}$, and $1.8 \mathrm{~km}$ at reservoir are also derived and evaluated. Temperature variations of the March model are obtained taking into account the seasonal changes in reservoir and inflow condition. Thermocline variations in the reservoir are modelled through the dam face, cross and longitudinal sections. Figs. 14, 15, and 16 show the contours of temperature fields for three measuring station cross-sections and different longitudinal sections in 3-D of the real dam reservoir. Figs 13 and 14 represent the three-dimensional plot of thermocline variation for Station-1 and along the Egrrekkaya dam reservoir. Since the temperature values of Sey River are equal to the average temperature of the water in the reservoir in March, temperatures do not change through cross-section in the Station-1. In this case, Sey river's entrance of the reservoir consists of overflow and plunging does not occur in any event. Overflow in Station1 is shown in Figs 13-14. 
Thermocline variations through the dam face, longitudinal and cross sections in the reservoir are given in Figs 15 and 16. Contrary to the Sey River's flow, Çeterek inflow river temperature $\left(3.6^{\circ} \mathrm{C}\right)$ and density is lower than the ambient water average temperature $\left(4.4^{\circ} \mathrm{C}\right)$ in March. Even a small difference in temperature causes the stratified flow and plunging in the reservoir. This stratified flow can clearly be seen in Figs 15-16. Therefore, the water temperatures in Stations 2 and 3 decrease from $4.45^{\circ} \mathrm{C}$ to $3.45^{\circ} \mathrm{C}$ throughout the reservoir depth. The stratified flows are formed due to the different warmth of stable and only inflow Çeterek river water. The run simulations for March show that initially the inflow Sey river water advances to Çeterek River entrance as overflow into the reservoir, and from there to downstream, consists of stratified flow into ambient reservoir water due to the temperature variations.

Figs 17 and 18 show the behavior of flow entrance of the Sey and Çeterek rivers and plunging point in the reservoir in March respectively. As can be seen from these figures, the entering current of the Sey River becomes attached to one wall. Therefore, typical attached wall jet flow forms at the reservoir entrance. However, since the inflow Sey River's temperature is equal to ambient water, plunging does not occur in 1st Station (Fig. 17). Therefore, overflow continues until the junction of Çeterek River. Generally, in this type of wall jet flow formations, wall jet flow and separations appear only at one side wall of the reservoir since plunging does not occur along the overflow. Wall jet flow, stall formation and velocity variation can clearly be defined from the simulation in Fig. 17.

It can be seen from Fig. 18 that since inflow Çeterek river temperature is smaller than ambient water, plunging and stratification are observed in the reservoir after the junction of Çeterek River. Altough the temperature difference between the inflow and ambient reservoir water is approximately $1^{\circ} \mathrm{C}$, stratified flow and temperature variations are clearly seen in Figs 15 and 16. As can be seen from the results of the model, the plunge location and entrance of Sey and Çeterek rivers affected the inlet condition, density and the divergence (convergence) angles of the ambient water. As observed from July simulation model, the plunge point, location and depth are never stabilized and plunge point continues to move back and forth based on the inflow water and environmental conditions of the dam.

Fig. 19 shows the plot of the thermocline contour sections, and variations on the side surface along the reservoir in March. As seen in Fig. 4, since the width of the reservoir decreases from $2360 \mathrm{~m}$ to $1975 \mathrm{~m}$, also the surface area of the reservoir gets smaller due to low reservoir levels in winter season. Decreasing reservoir volume and temperature variation can clearly also be seen in Fig. 19. Similar to Fig. 15, although the reservoir temperature variation is almost $1^{\circ} \mathrm{C}$, stratified temperature and shallow water temperature areas in shoreline of the reservoir are clearly seen in Fig. 19. The determination of these temperature variations is important for water quality and pollution problems. These results show that the present mathematical model can be used in defining the reservoir flow variation also for the cold season.

\section{CONCLUSION}

A simulation model of a real dam reservoir is studied in three dimensions. The study was designed to determine the inflow behavior of a real dam reservoir throughout the year. Model simulations are obtained for different seasons in order to determine the variation of reservoir flow during the year. The simulation analysis offers a useful insight into the development, variation of ambient reservoir flow and the impacts of the different seasons on the reservoir flow.

The model results are compared with field measurements. The results are found to be in accordance with the actual values measured. The following observations and conclusions can be made:

The developed mathematical model can successfully simulate the turbulent density flow under realistic reservoir conditions.

In the numerical approach used, the plunge regions need not be isolated from the rest of the reservoir, so that the river inflow can be simulated along the reservoir in 3-D.

Overflow, plunging and density flow, wall-jet flow (attached flow), and recirculation zone development into the reservoir can be well defined in the temperature and velocity fields in the model simulation results.

The effects of seasonal temperature variations in reservoir body and catchment can be evaluated by simulations.

Flows consisting of the real dam reservoir are greatly affected by the reservoir cross-sections and shapes, seasonal changes, and variations in the river inflow conditions.

If the cross-sections of the river valley under the reservoir (e.g. taken from the maps), mean temperature of the ambient reservoir water, discharge and temperature of incoming river flow are known, then the dam reservoir flows occurring during different periods of the year and the reservoir parameters can easily be estimated from the mathematical model simulation results.

Fresh water sources are dwindling and becoming contaminated throughout the world due to environmental problems and fast growing population. Dam reservoirs are one of the most commonly used sources of fresh water. In this sense, the present model can also be utilized for the water quality modeling and management, and habitat assessment in a real dam reservoir.

Acknowledgements. This study was supported by The Scientific \& Technological Research Council of Turkey (TÜBITAK) under Grant No: 106Y294. The Authors also would like to express his gratitude to Turan Arslan (Mustafa Kemal University, Civil Engineering Faculty, Hatay-Turkey) for his constructive criticism and help.

\section{REFERENCES}

Akiyama, J., Stefan, G.H., 1984. Plunging flow into a reservoir: theory. J. Hydraul. Eng. ASCE, 110, 484-489.

Alavian, V., 1986. Behavior of density current on an incline. J. Hydraul. Eng. ASCE, 112, 27-42.

Alavian, V., Ostrowski, P., 1992. Use of density current to modify thermal structure of TVA reservoirs. J. Hydraul. Eng. ASCE, 118, 5, 688-706.

Alavian, V., Jirka, G.H., Denton, R.A., Johnson, M.C., Stefan, H.G., 1992. Density Current Entering Lakes and Reservoirs, J. Hydraul. Eng. ASCE, 118, 1464-1489.

Bournet, P.E., Dartus, D., Tassin, B., Vincon-Leite, B., 1999. Numerical investigation of plunging density current. J. Hydraul. Eng. ASCE, 125, 584-594.

Bradford, S.F., Katopodes, N.D., Parker, G., 1997. Analysis of turbid underflows. J. Hydraul. Eng. ASCE, 123, 5, 420-431.

Choi, S.U., Garcia, M.H., 2002. k-e turbulence modeling of density currents developing two-dimensionally on a slope. J. Hydraul. Eng. ASCE, 128, 1, 55-63.

Chung, S.W., Gu, R., 1998. Two dimensional simulations of contaminant currents in stratified reservoir. J. Hydraul. Eng. ASCE, 124, 704-711. 
Dallimore, C.J., Imberger, J., Hodges, B.R., 2004. Modeling a plunging underflow. J. Hydraul. Eng. ASCE, 130, 11, 1068-1076.

De Cesare, G., Boillat, J.L., Schleiss, A.J., 2006. Circulation in stratified lakes due to flood-induced turbidity currents. J. Hydraul. Eng. ASCE, 132, 11, 1508-1517.

DSI (Turkish General Directorate of State Hydraulic Works), 2001. Eğrekkaya dam reservoir and basin pollution research report, Project Report, Ankara, Turkey.

Farrell, G.J., Stefan, H.G., 1986. Buoyancy induced plunging flow into reservoirs and coastal regions. Project Report No. 241, St. Anthony falls Hydraul. Lab, University of Minnesota.

Farrell, G.J., Stefan, H.G., 1988. Mathematical modeling of plunging reservoir flows. J. Hydraul. Res., 26, 525-537.

Fischer, H.B., Smith, R.D., 1983. Observation of transport to surface waters from a plunging inflow to Lake Mead. Limnol Oceanogr., 28, 258-272.

FLUENT 6.3, 2008. User's Guide. FLUENT incorporated, New Hampshire, United States of America.

Ford, D.E., Johnson, M.C., Monismith, S.G., 1980. Density inflows to DeGray lake, Arkansas. In: Second international symposium on stratified flows, IAHR, Trondheim, Norway.

Fukushima, Y., Watanabe, M., 1990. Numerical simulation of density underflow by the k-e turbulence model. J. Hydrosci. Hydraul. Eng., 8, 31-40.

Garcia, M.H., 1993. Hydraulic jumps in sediment-driven bottom currents. J. Hydraul. Eng., 119, 1094-1117.

Garcia, M.H,. 1994. Depositional turbidity currents laden with poorly sorted sediment. J. Hydraul. Eng., 120, 1240-1263.

Hassan, M.A, Egozi, R., Parker, G., 2006. Experiments on the effect of hydrograph characteristics on vertical grain sorting in gravel bed rivers. Water Resour. Res., 42, 9.

Hauenstein, W., Dracos, T., 1984. Investigation of plunging density currents generated by inflows in lakes. J. Hydraul. Res., 22, 157-179.

Hebbert, B., Imberger, J., Loh, I., Paterson, J., 1979. Collie river underflow into the Wellington reservoir. J. Hydraul. Div. ASCE, 105, HY5, 533-545.

Johnson, T.R., Stefan, H.G., 1988. Experimental study of density induced plunging flow into reservoirs and coastal regions. Project Report No. 245, St. Anthony falls Hydraul. Lab., University of Minnesota.

Johnson, T.R., Farrell, G.J., Ellis, C.R., Stefan, H.G., 1987a. Negatively buoyant flow in diverging channel: part I. Flow regimes. J. Hydraul. Eng. ASCE, 113, 716-730.

Johnson, T.R., Ellis, C.R., Farrell, G.J., Stefan, H.G., 1987b. Negatively buoyant flow in diverging channel: part II. 3D flow field regimes. J. Hydraul. Eng., ASCE, 113, 731-742.

Kassem, A., Imran, J., Khan, J.A., 2003. Three-dimensional modeling of negatively buoyant flow in diverging channels. J. Hydraul. Eng., 129, 12, 936-947.

Kostic, S., Parker, G., 2003. Progradational sand-mud deltas in lakes and reservoirs. Part 1 . Theory and numerical modeling. J. Hydraul. Res., 41, 2, 127-140.

Kostic, S., Parker, G., 2006. The response of turbidity currents to a canyonfan transition: internal hydraulic jumps and depositional signatures. J. Hydraul. Res., 44, 5, 631-653.

Lamb, M.P., Hickson, T., Marr, J.G., Sheets, B., Paola, C., Parker, G., 2004. Surging versus continuous turbidity currents: flow dynamics and deposits in an experimental intraslope basin. J. Sediment. Res., 74, 148-155.

Lamb, M.P., Toniolo, H., Parker, G., 2006. Trapping of sustained turbidity currents by intraslope minibasins. Sedimentology, 53, 1, 147-160.
Launder, B.E, Spalding, D.B., 1972. Mathematical Models of Turbulence. Academic Press, New York.

Launder, B.E., Spalding, D.B., 1974. The numerical computation of turbulent flows. Comput. Methods Appl. Mech. Eng., 3, 269-289.

Lee, H.Y., Yu, W.S., 1997. Experimental study of reservoir turbidity current. J. Hydraul. Eng., 123, 6, 520-528.

Parker, G., Garcia, M.H., Fukushima, Y., Yu, W., 1987. Experiments on turbidity currents over an erodible bed. J. Hydraul. Res., IAHR. 25, 123-147.

Patankar, S.V., Spalding D.B., 1972. A calculation procedure for heat, mass and momentum transfer in three dimensional parabolic flows. Int. J. Heat Mass Transfer, 15, 1787.

Patankar, S.V. 1980. Numerical Heat Transfer and Fluid Flows. McGraw-Hill, New York.

Pedlosky, J., 1987. Geophysical Fluid Dynamics. SpringerVerlag, New York.

Rodi, W., 1987. Example of calculation methods for flow and mixing in stratified fluids. J. Geophys. Res., 92, 5305-5328.

Savage, S.B., Brimberg, J., 1975. Analysis of plunging phenomena in water reservoirs. J. Hydraul. Res., 13, 2, 187-204.

Singh, B., Shah, C.R., 1971. Plunging phenomenon of density currents in reservoirs. La Houille Blanche, 26, 59-64.

Stefan, H.G., 1973. High concentration turbidity currents in reservoirs. IAHR, 1, 341-352.

Toniolo, H., Lamb, M., Parker, G., 2006. Depositional turbidity currents in diapiric minibasins on the continental slope: formulation and theory. J. Sediment. Res., 76, 5-6,783-797.

Üneş, F., 2004. Investigation of effects of coriolis forces and outlet levels on reservoir flow using mathematical model. Istanbul Technical University, Ph.D. Dissertation, Institute of Science and Technology, Istanbul.

Üneş, F., 2005. Investigation of temporary variation of plunging point caused by density plunging reservoir flow using mathematical modeling,. Turkish Chamb. Civil. Eng. Tech. J., Digest 2005, 1027-1042.

Üneş, F., 2008a. Analysis of plunging phenomenon in dam reservoirs using three dimensional density flow simulations. Canadian Journal of Civil Engineering, 35, 1138-1151.

Üneş, F., 2008b. Investigation of density flow in dam reservoirs using a three-dimensional mathematical model including Coriolis effect. Computers \& Fluids, 37, 1170-1192.

Üneş, F., 2009. Investigation of Flows into a Real Dam Reservoir Using Three Dimensional Mathematical Model. Project Report No. 106Y294, TÜBİTAK, Ankara.

Üneş, F., 2010. Prediction of density flow plunging depth in dam reservoirs: an artificial neural network approach. Clean - Soil, Air, Water, 38, 3, 296-308.

Üneş, F., Ağıralioğlu, N., 2004. Investigation of density plunging reservoir flow using mathematical modeling. ITU J., 1/d, 3,6 .

Violet, J., Sheets, B., Pratson, L., Paola, C., Beaubouef, R., Parker G., 2005. Experiment on turbidity currents and their deposits in a model 3D subsiding minibasin. J. Sediment Res., 75, 5, 820-843.

Wright, S., Parker, G., 2004. Density stratification effects in sand-bed rivers. J. Hydraul. Eng. ASCE, 130, 8, 783-795.

Yu, W.S., Lee, H.Y., Hsu, S.H.M., 2000. Experiments on deposition behavior of fine sediment in a reservoir. J. Hydraul. Eng., 126, 12, 912-920.

Received 4 December 2013 Accepted 22 September 2014

Note: Figures 3-19 and Tables 2-3 can be found in the web version of this article. 


\section{SUPPLEMENTARY MATERIAL}

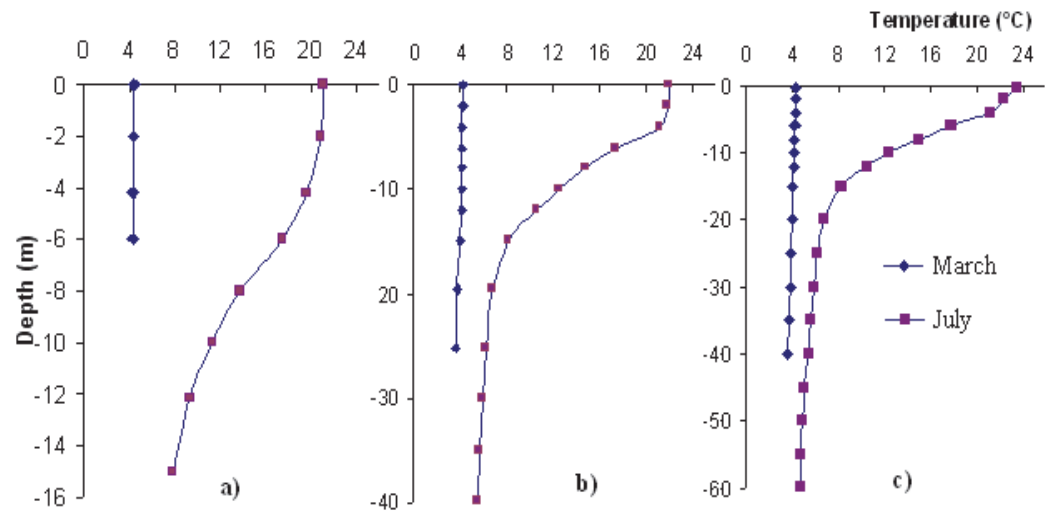

Fig. 3. Observed temperature variation for Eğrekkaya dam at three gauging stations: a) Sampling station 1; b) Sampling station 2; c) Sampling station 3.
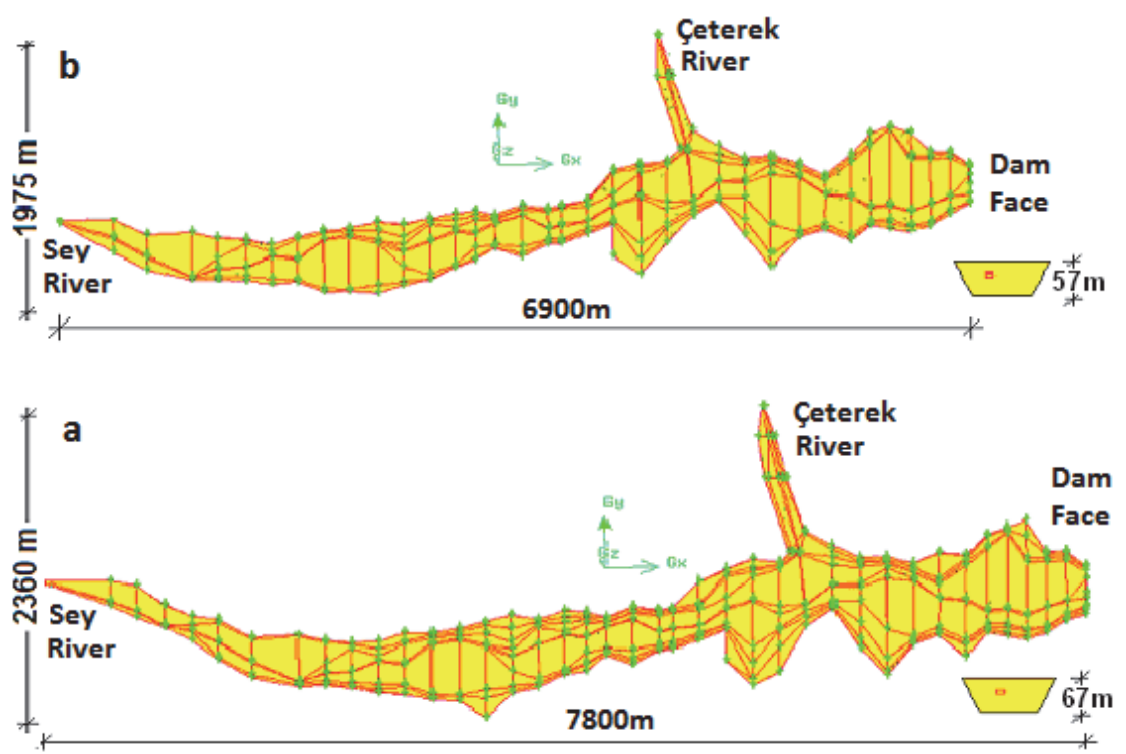

Fig. 4. Cross-section points at each 50-100m a) layout and dam face section in July b) layout and dam face section in March.

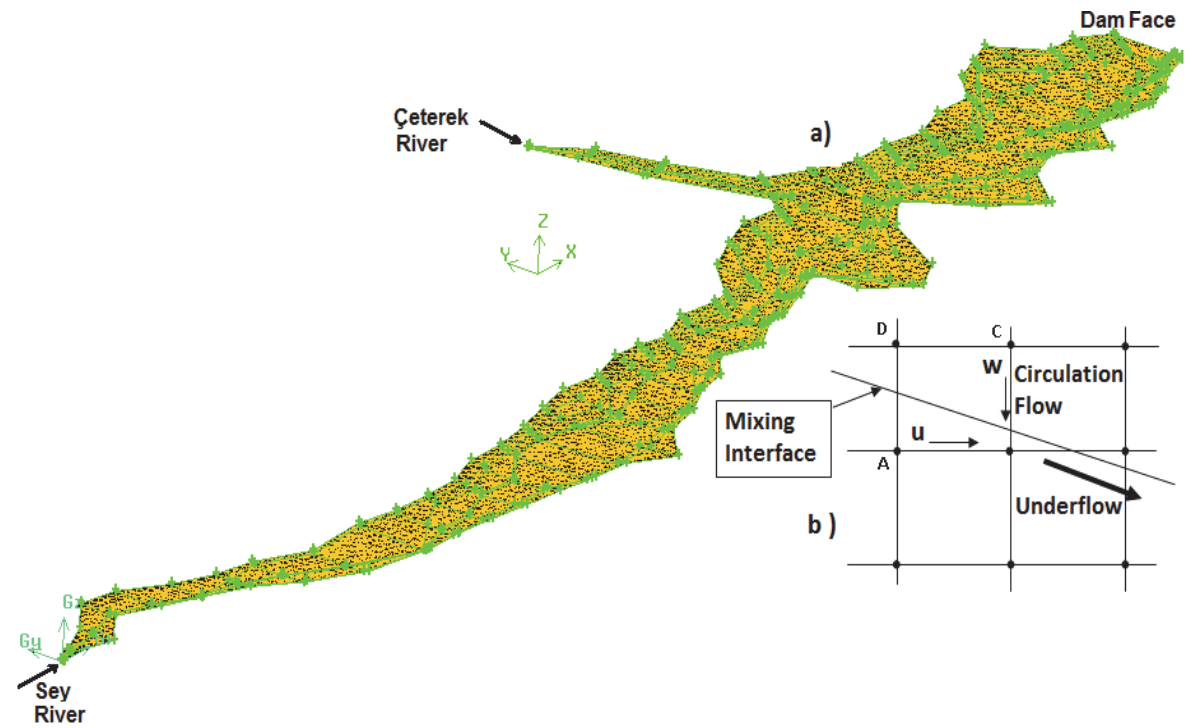

Fig. 5. a) Real three-dimensional Eğrekkaya dam reservoir mesh shape (Typical dam perspective view from upstream) b) Typical thermocline stratified flow mesh grid line to skewness error. 


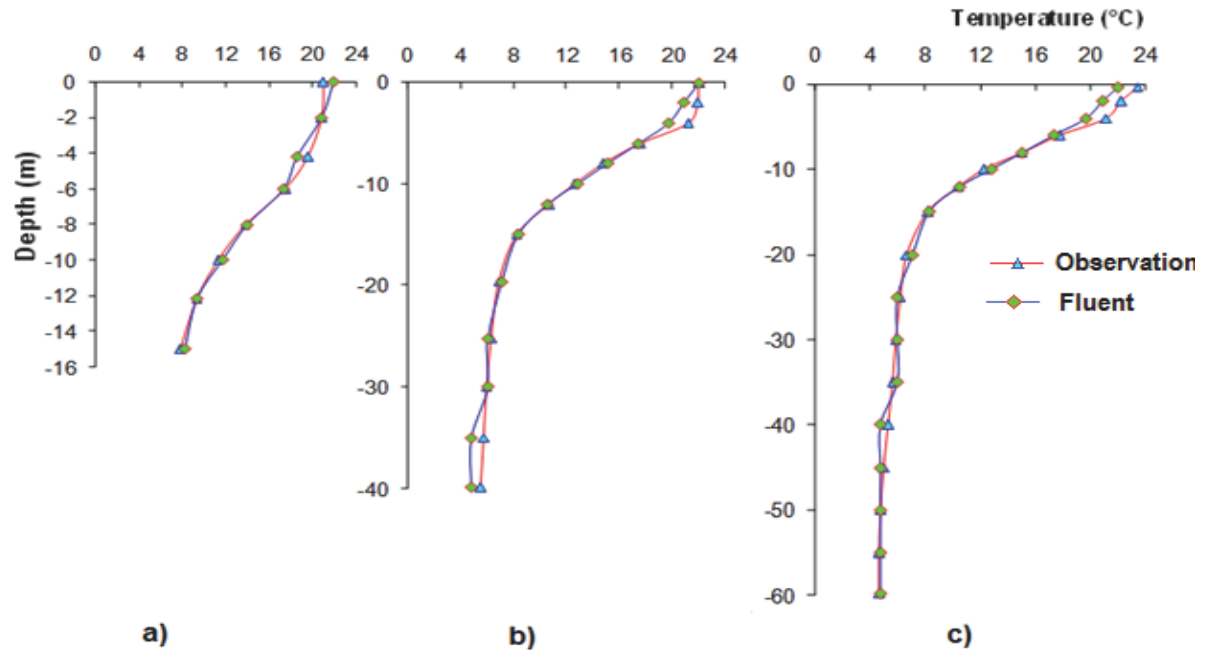

Fig. 6. Comparison of observed and present numerical model temperatures in July; a) $1^{\text {st }}$ Station, b) $2^{\text {nd }}$ Station, c) $3^{\text {rd }}$ Station.

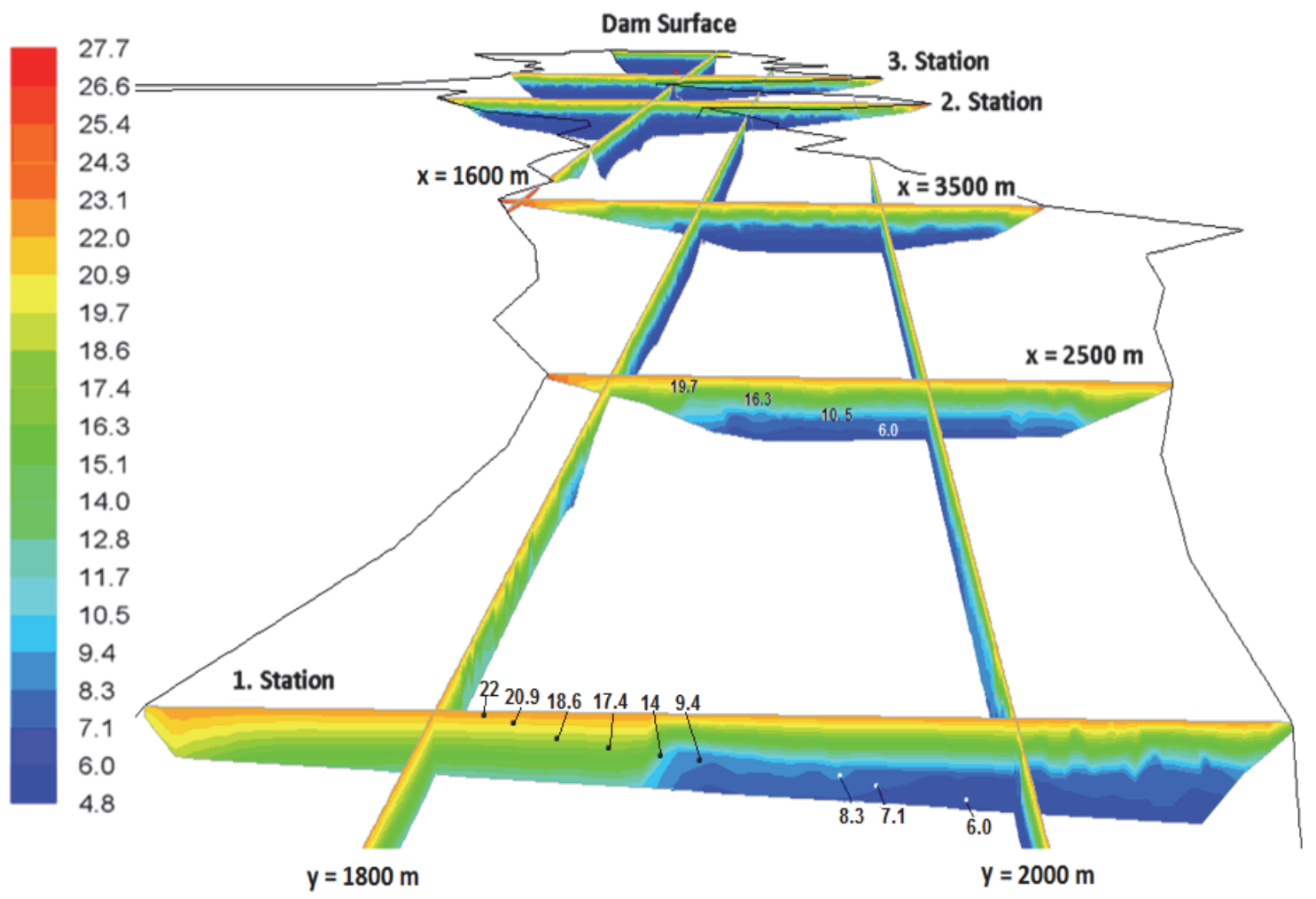

Fig. 7. Cross sectional view of thermocline variations at different water depth at Station 1 and various cross-sections along the Eğrekkaya reservoir, and longitudinal section variations of thermocline at 1600, 1800 and $2000 \mathrm{~m}$ in July. 


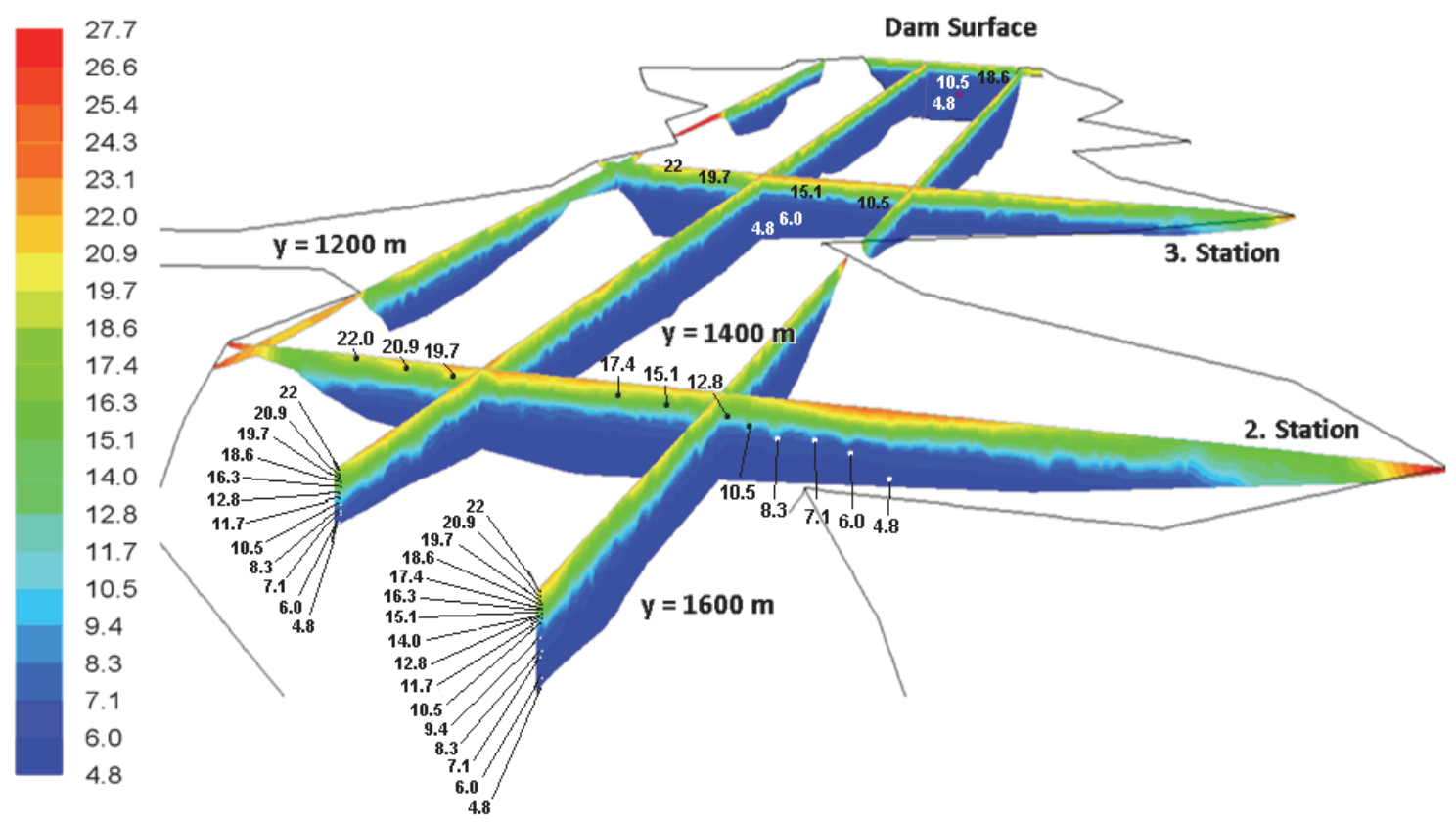

Fig. 8. Cross sectional view of thermocline variations at different water depths at Station 2, 3, and on the dam face, and longitudinal crosssections at 1200, 1400 and $1600 \mathrm{~m}$ in July.
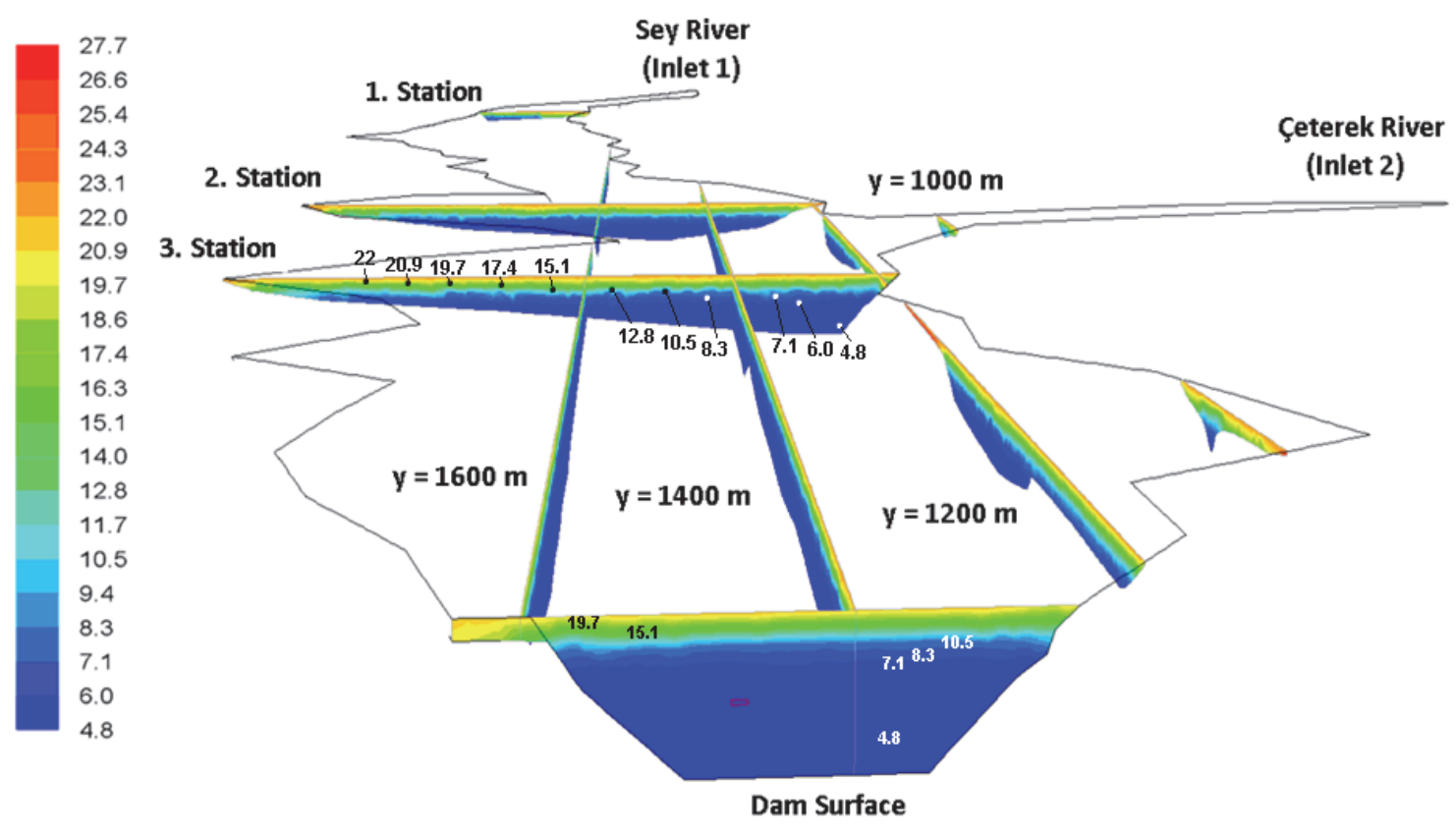

Fig. 9. Cross sectional view of thermocline variations at different water depth at dam face and Station 3 and 2, and longitudinal crosssections at 1200,1400 and $1600 \mathrm{~m}$ in July. 


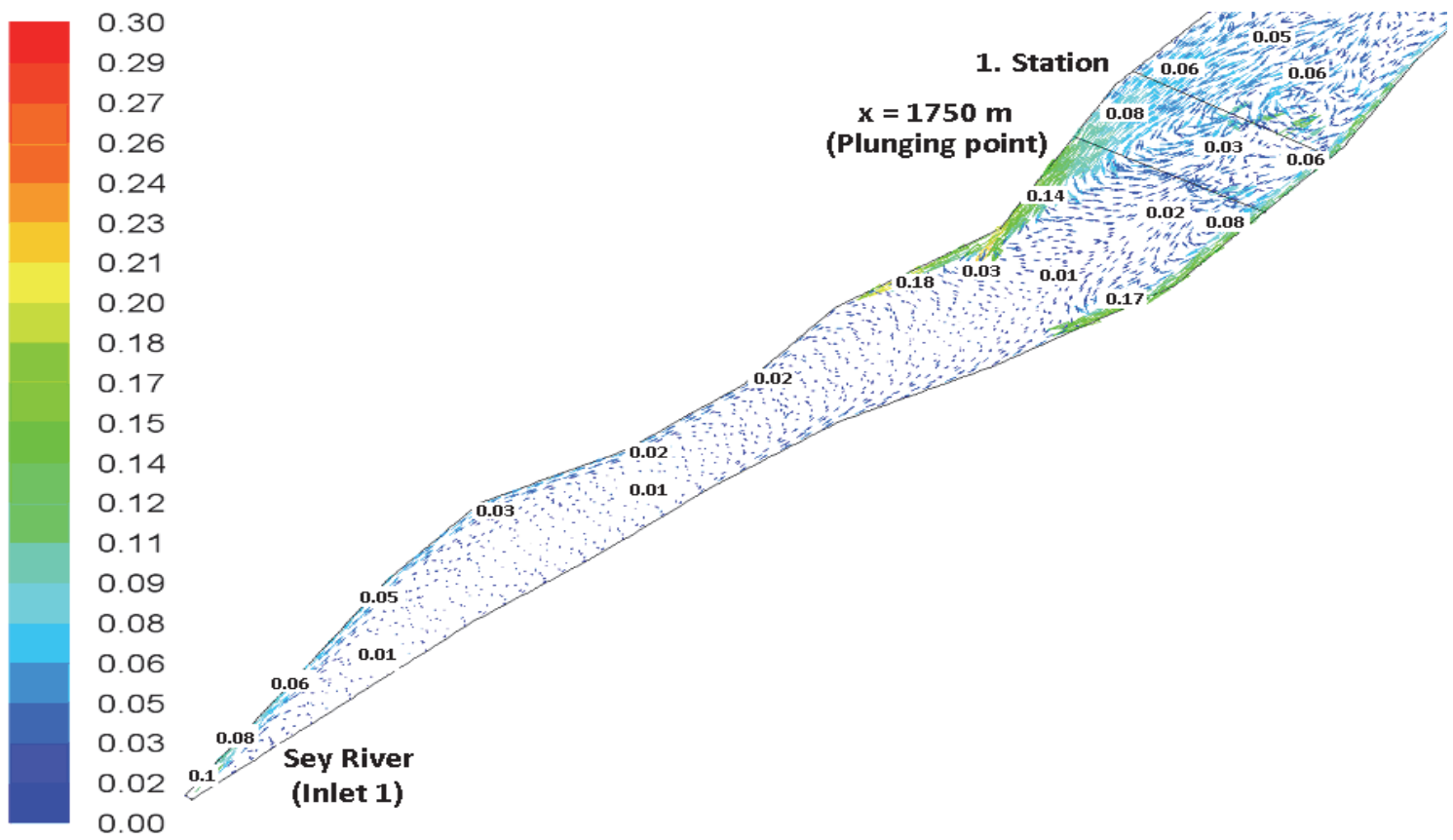

Fig. 10. Typical reservoir velocity vectors on the water surface for Sey River's inlet, wall jet flow and plunging point in July.
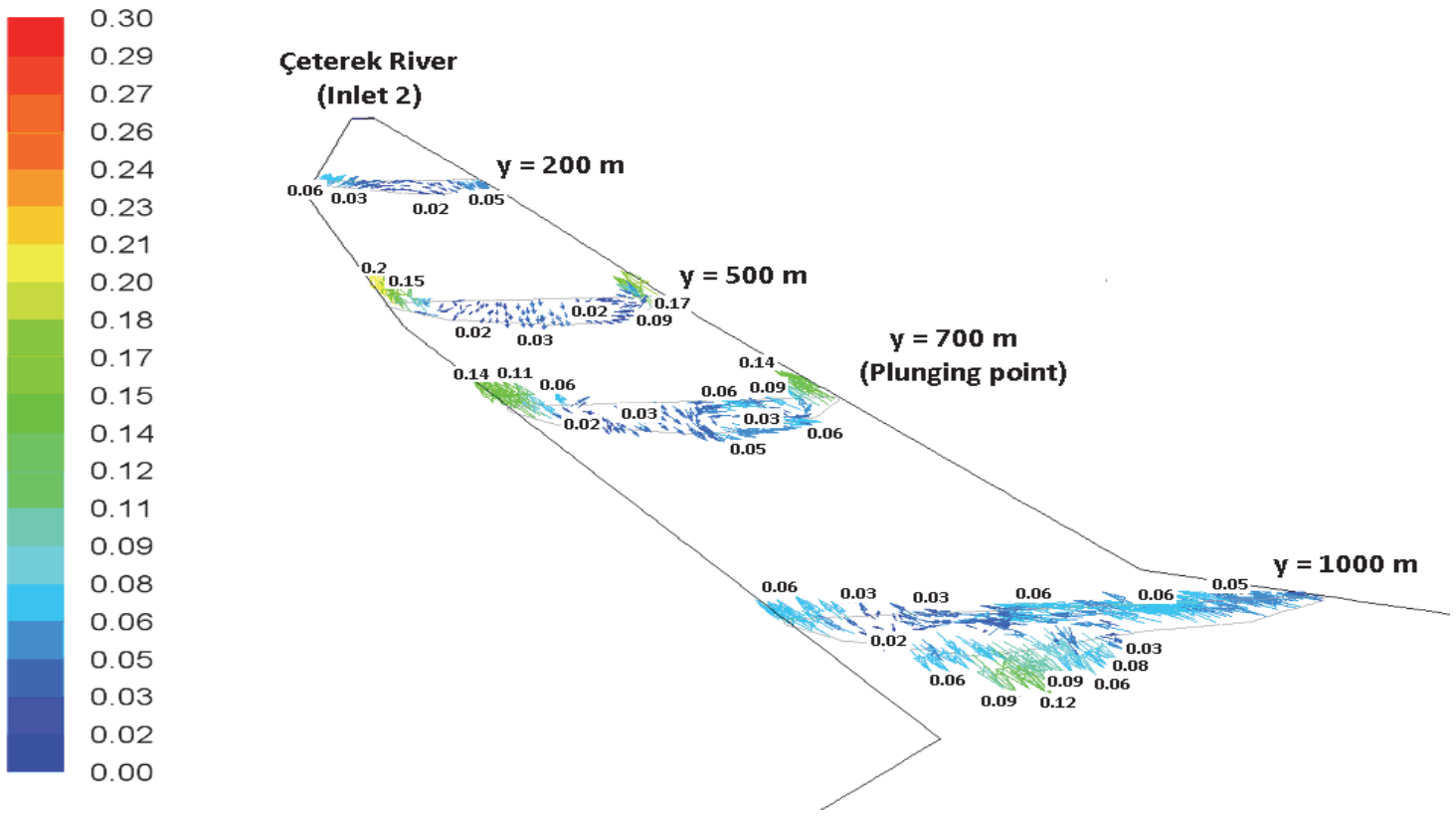

Fig. 11. Typical reservoir velocity vectors of sections for Çeterek River's inlet, wall jet flow and plunging point in July. 


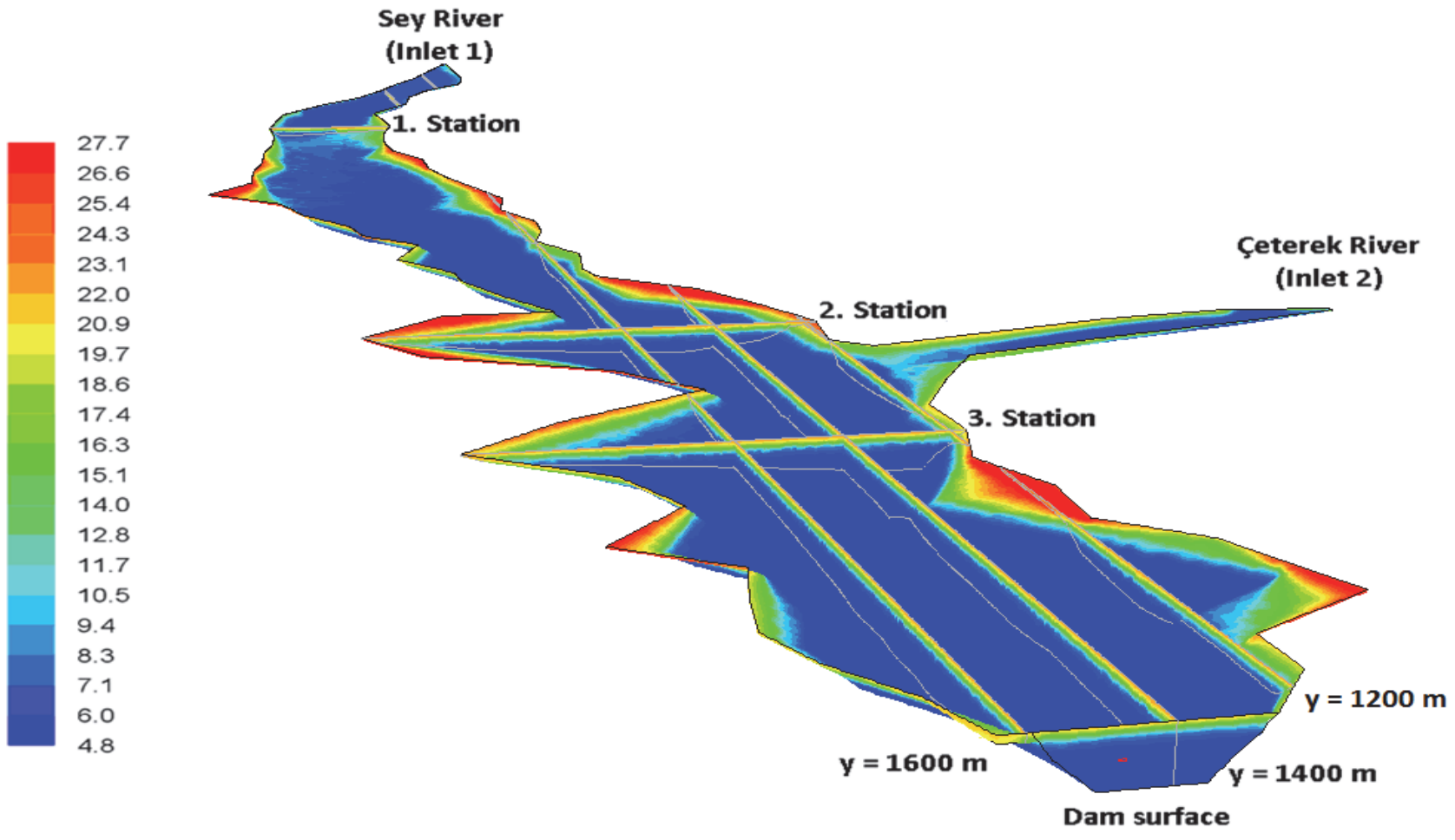

Fig. 12. Temperature variation of side surfaces of the reservoir and cross-sections in July (Dam model perspective view from downstream).

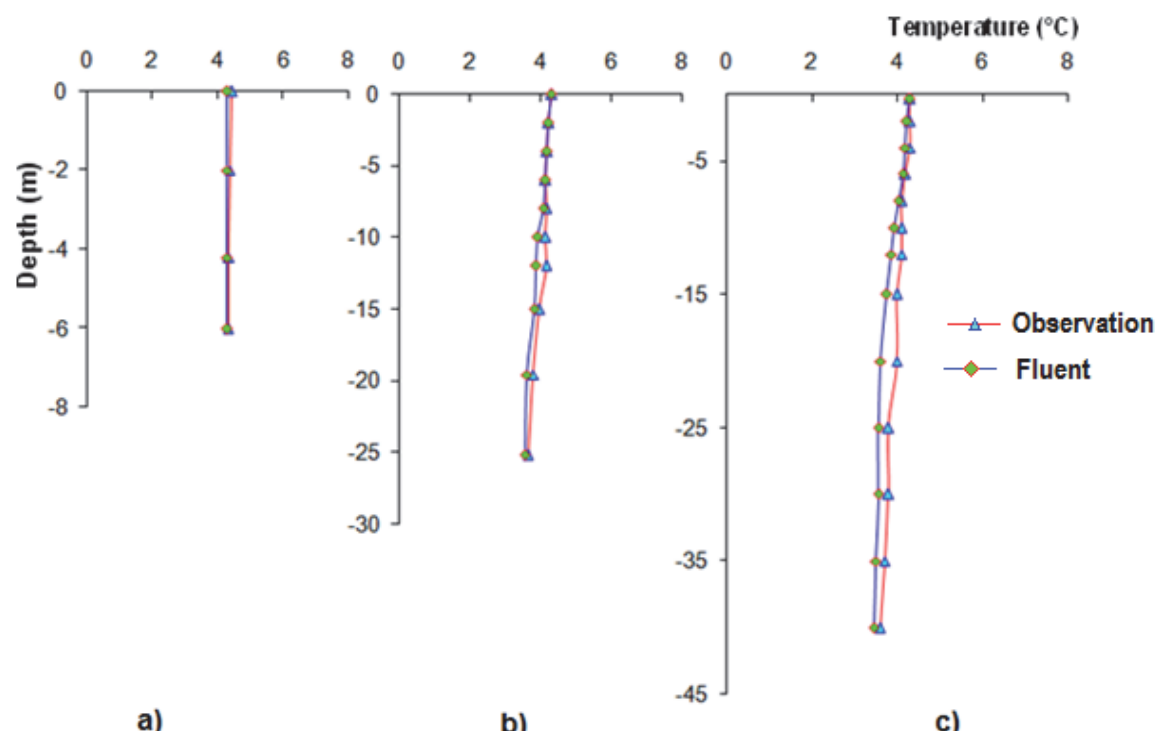

Fig. 13. Comparison of observed and present numerical model temperature in March; a) $1^{\text {st }}$ Station, b) $2^{\text {nd }}$ Station, c) $3^{\text {rd }}$ Station. 


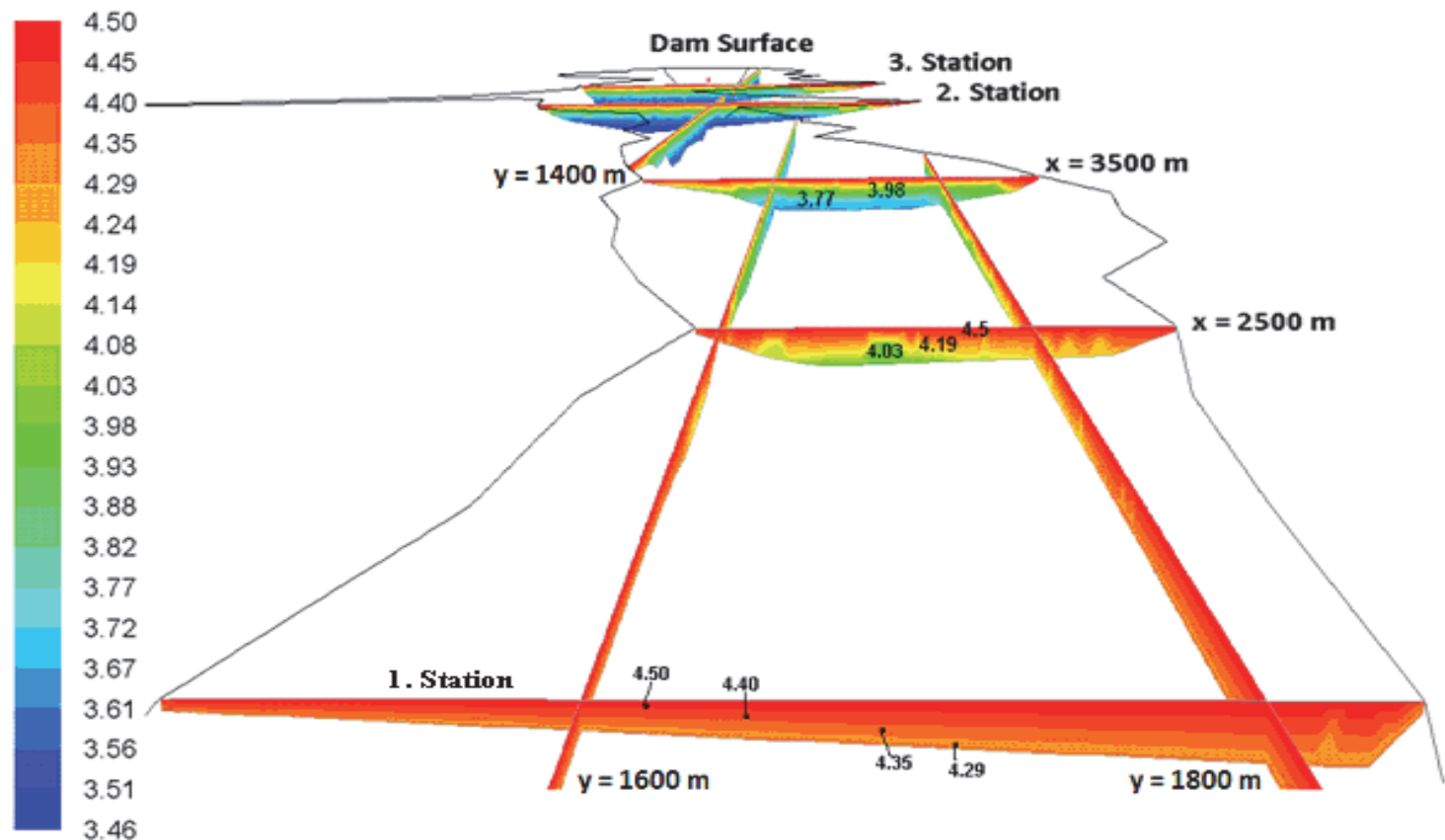

Fig. 14. Cross sectional view of thermocline variations at different water depth at Station 1 and various cross-sections at 2500 and $3000 \mathrm{~m}$, and longitudinal section at 1400, 1600 and $1800 \mathrm{~m}$ in March.

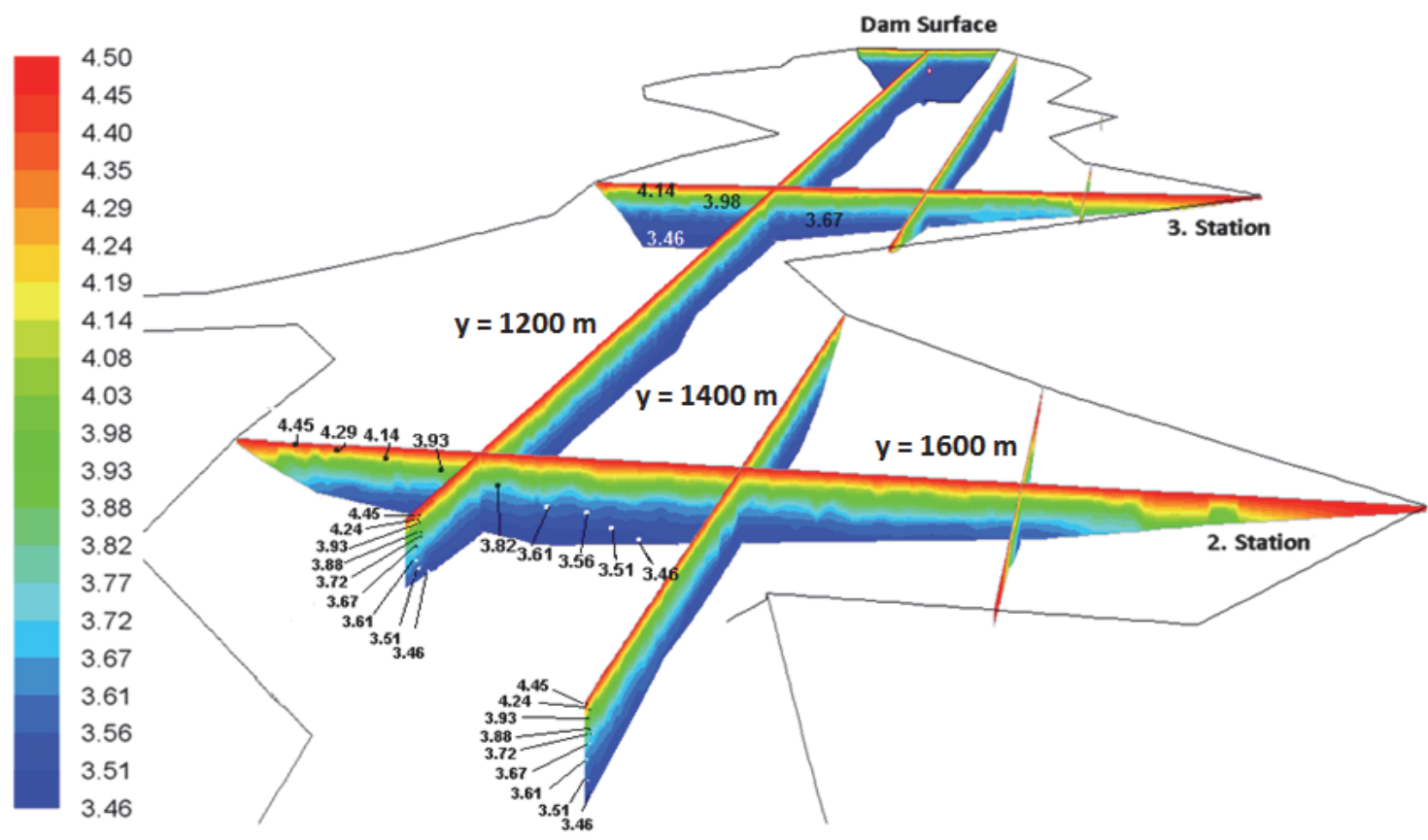

Fig. 15. Cross sectional view of thermocline variations at different water depths at Station 2, 3, and on the dam face, and longitudinal crosssections at 1200, 1400 and $1600 \mathrm{~m}$ in March. 


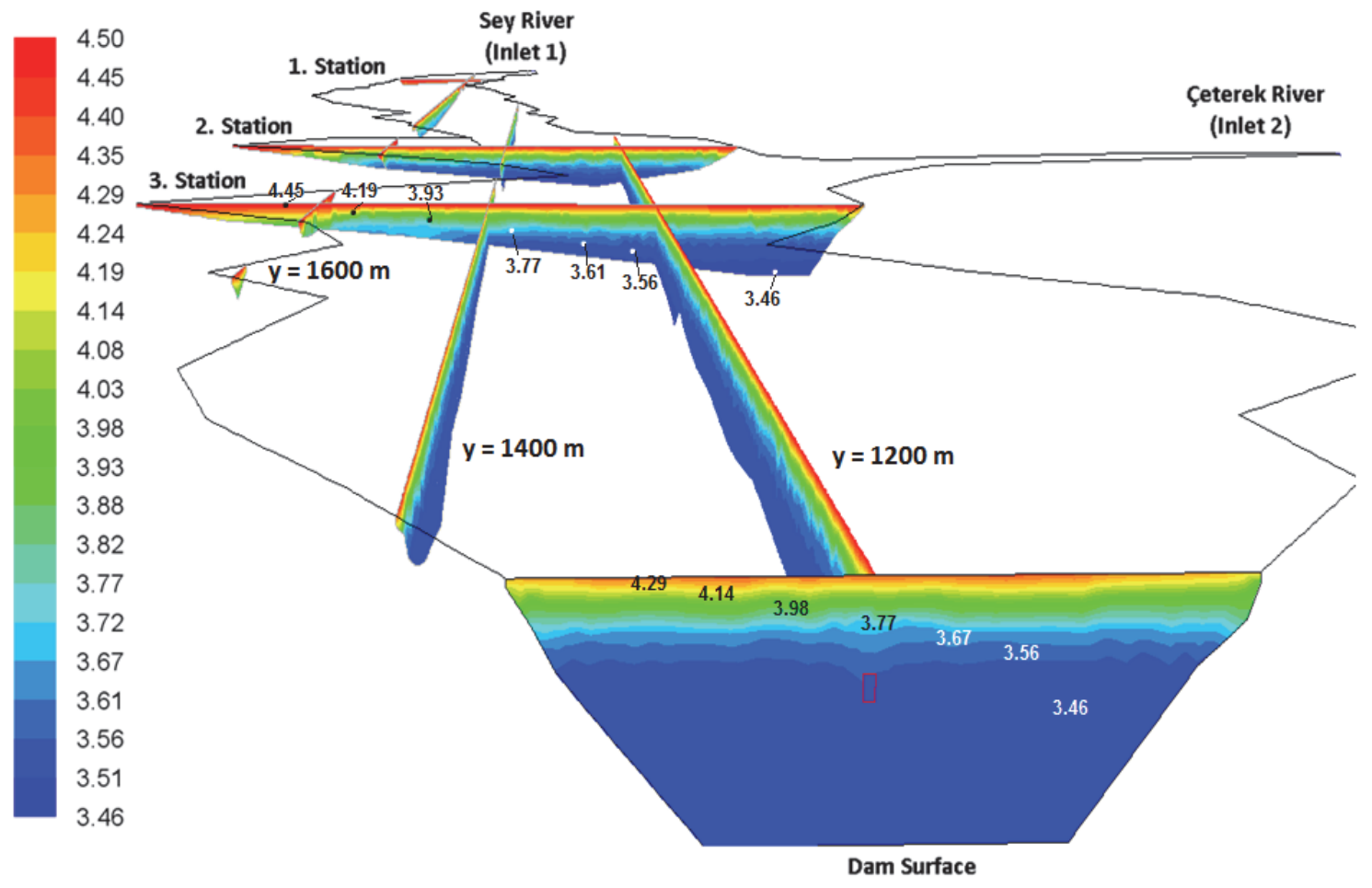

Fig. 16. Cross sectional view of thermocline variations at different water depth at dam face and Station 3 and 2, and longitudinal crosssections at 1200, 1400 and $1600 \mathrm{~m}$ in March.
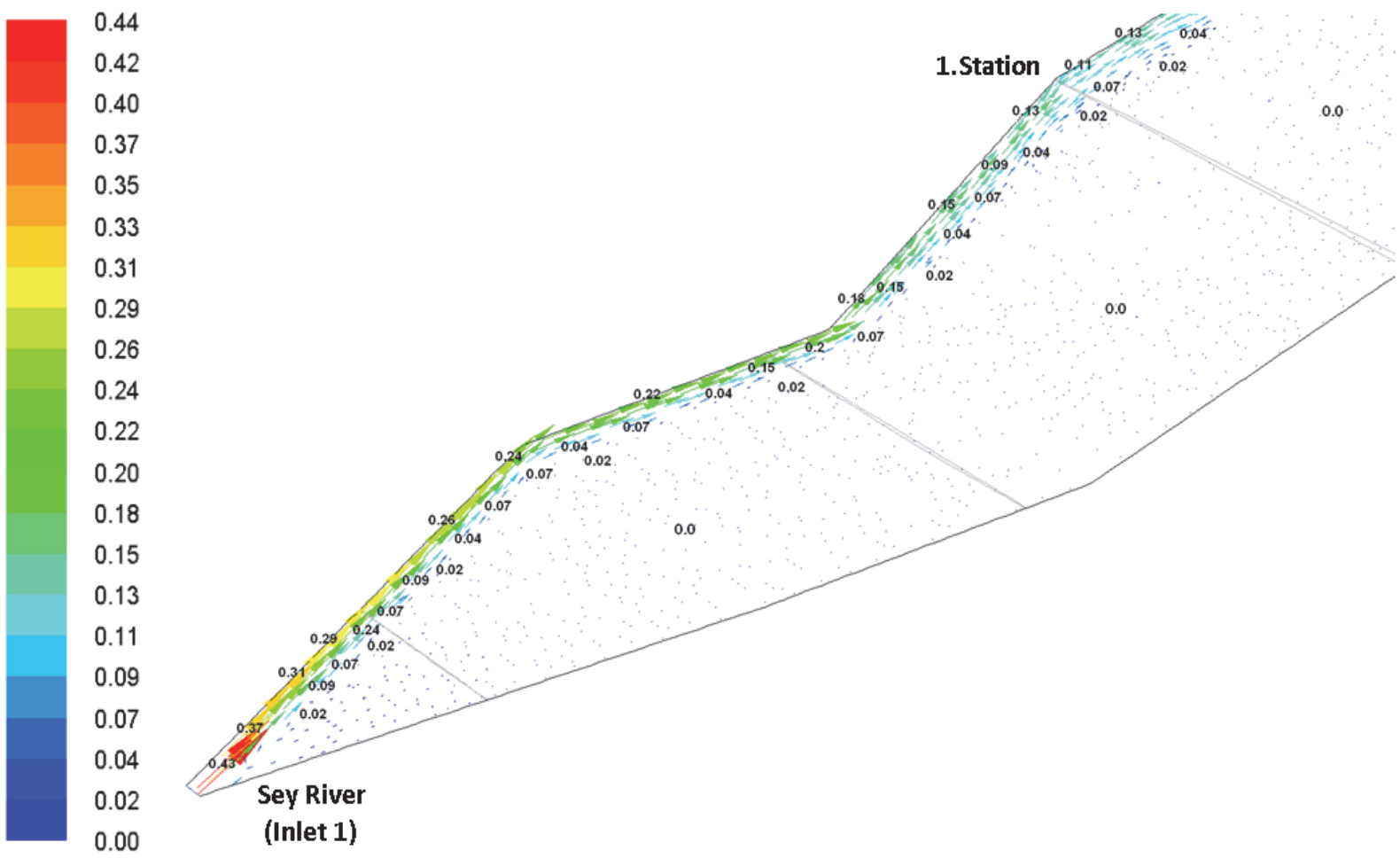

Fig. 17. Typical reservoir velocity vectors on the water surface for Sey River's inlet wall jet flow and plunging point in March. 


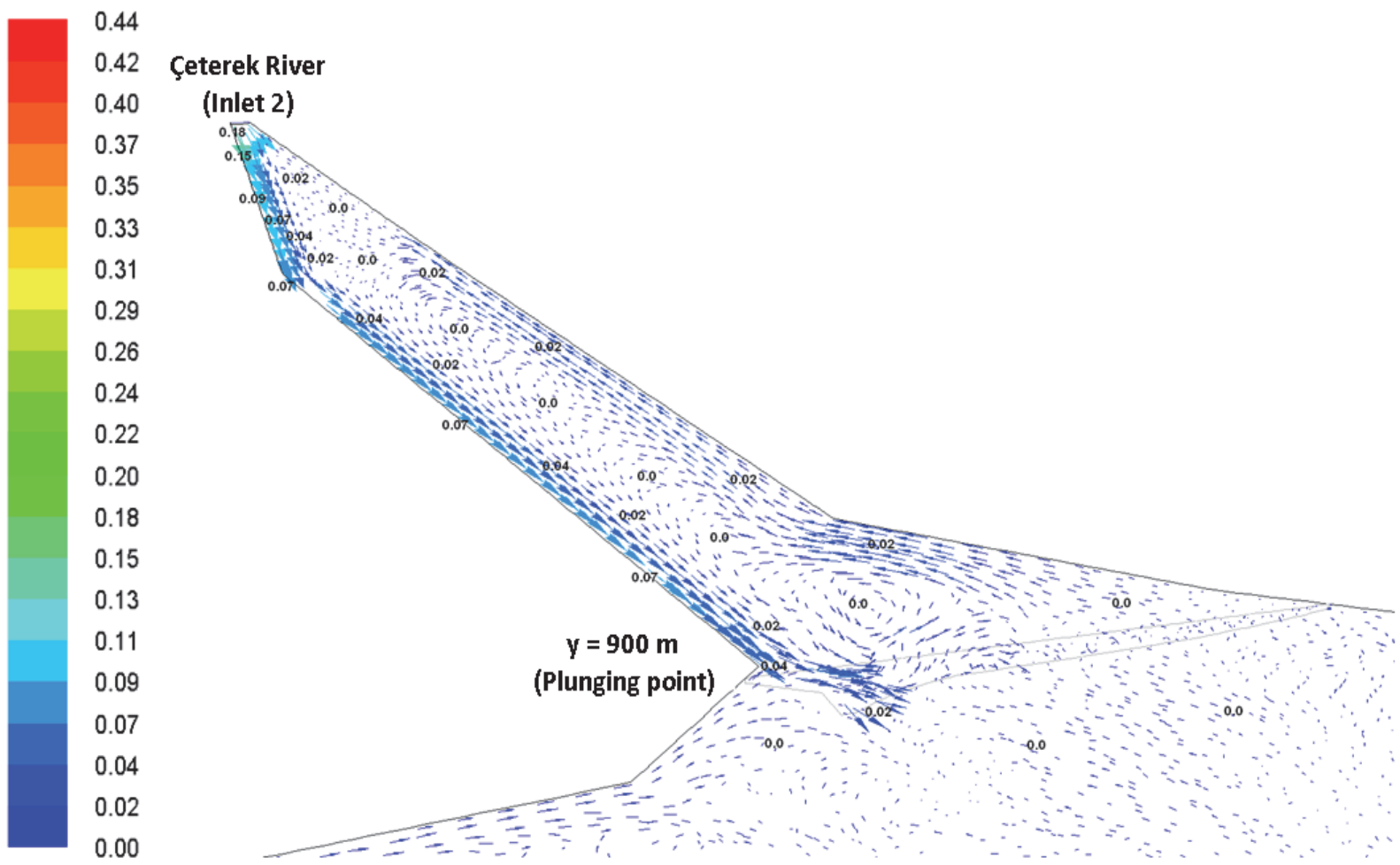

Fig. 18. Typical reservoir velocity vectors on the water surface for Çeterek River's inlet wall jet flow and plunging point in March.

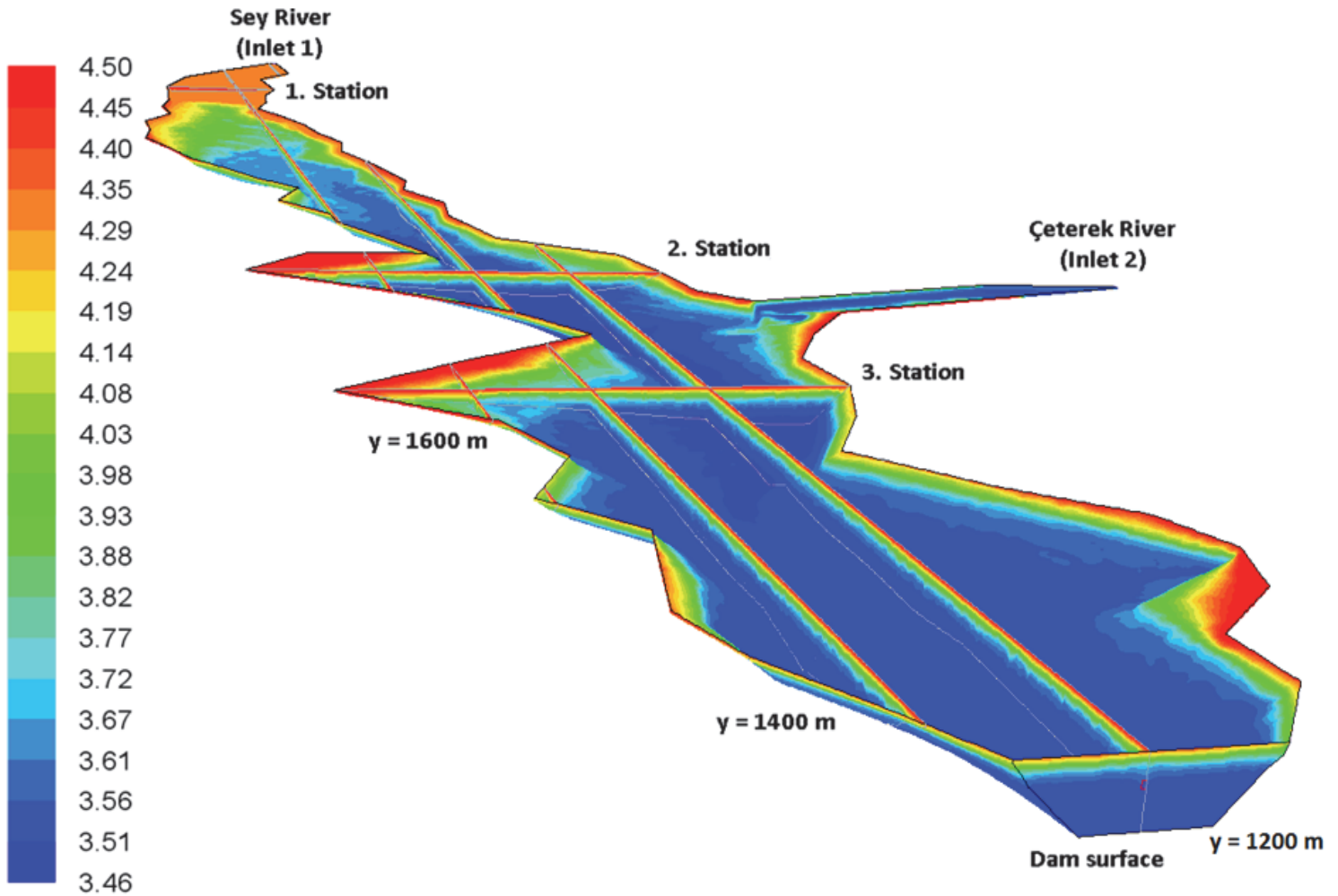

Fig. 19. Temperature variation of side surfaces of the reservoir and cross-sections in March (Dam model perspective view from downstream). 
Table 2. Temperature-Depth values in July at $1^{\text {st }}, 2^{\text {nd }}$ and $3^{\text {rd }}$ stations for measured and obtained results.

\begin{tabular}{cccccccccc}
$\begin{array}{c}\text { Depth } \\
(\mathrm{m})\end{array}$ & \multicolumn{3}{c}{$1^{\text {st }}$ Station } & \multicolumn{9}{c}{$2^{\text {nd }}$ Station } & \multicolumn{3}{c}{$3^{\text {rd }}$ Station } \\
\cline { 2 - 10 }$\left({ }^{\circ} \mathrm{C}\right)$ & $\left(\begin{array}{c}\text { Model } \\
\left({ }^{\circ} \mathrm{C}\right)\end{array}\right.$ & $\begin{array}{c}\text { Error } \\
(\%)\end{array}$ & $\begin{array}{c}\text { Measured } \\
\left({ }^{\circ} \mathrm{C}\right)\end{array}$ & $\begin{array}{c}\text { Model } \\
\left({ }^{\circ} \mathrm{C}\right)\end{array}$ & $\begin{array}{c}\text { Error } \\
(\%)\end{array}$ & $\begin{array}{c}\text { Measured } \\
\left({ }^{\circ} \mathrm{C}\right)\end{array}$ & $\begin{array}{c}\text { Model } \\
\left({ }^{\circ} \mathrm{C}\right)\end{array}$ & $\begin{array}{c}\text { Error } \\
(\%)\end{array}$ \\
\hline-0.3 & 21.03 & 22 & 4.6 & 22 & 22 & 0.0 & 23.44 & 22 & 6.1 \\
-2 & 20.86 & 20.9 & 0.2 & 21.92 & 20.9 & 4.7 & 22.3 & 20.9 & 6.3 \\
-4 & 19.6 & 18.6 & 5.1 & 21.18 & 19.7 & 7.0 & 21.16 & 19.7 & 6.9 \\
-6 & 17.5 & 17.4 & 0.6 & 17.52 & 17.4 & 0.7 & 17.78 & 17.4 & 2.1 \\
-8 & 13.77 & 14 & 1.7 & 14.83 & 15.1 & 1.8 & 15.02 & 15.1 & 0.5 \\
-10 & 11.29 & 11.7 & 3.6 & 12.56 & 12.8 & 1.9 & 12.34 & 12.8 & 3.7 \\
-12 & 9.32 & 9.4 & 0.9 & 10.66 & 10.5 & 1.5 & 10.46 & 10.5 & 0.4 \\
-15 & 7.8 & 8.3 & 6.4 & 8.19 & 8.3 & 1.3 & 8.25 & 8.3 & 0.6 \\
-20 & - & - & - & 6.8 & 7.1 & 4.4 & 6.71 & 7.1 & 5.8 \\
-25 & - & - & - & 6.26 & 6 & 4.2 & 6.18 & 6 & 2.9 \\
-30 & - & - & - & 5.91 & 6 & 1.5 & 5.85 & 6 & 2.6 \\
-35 & - & - & - & 5.74 & 4.8 & 16.4 & 5.62 & 6 & 6.8 \\
-40 & - & - & - & 5.52 & 4.8 & 13.0 & 5.36 & 4.8 & 10.4 \\
-45 & - & - & - & - & - & - & 5.04 & 4.8 & 4.8 \\
-50 & - & - & - & - & - & - & 4.81 & 4.8 & 0.2 \\
-55 & - & - & - & - & - & - & 4.72 & 4.8 & 1.7 \\
-59.8 & - & - & - & - & - & - & 4.7 & 4.8 & 2.1 \\
\hline Mean Error Percentage: & & 2.9 & & & 4.5 & & 3.8
\end{tabular}

Table 3. Temperature-Depth values in March at $1^{\text {st }}, 2^{\text {nd }}$ and $3^{\text {rd }}$ stations for measured and obtained results.

\begin{tabular}{|c|c|c|c|c|c|c|c|c|c|}
\hline \multirow{2}{*}{$\begin{array}{l}\text { Depth } \\
\text { (m) }\end{array}$} & \multicolumn{3}{|c|}{$1^{\text {st }}$ Station } & \multicolumn{3}{|c|}{$2^{\text {nd }}$ Station } & \multicolumn{3}{|c|}{$3^{\text {rd }}$ Station } \\
\hline & $\begin{array}{c}\text { Measured } \\
\left({ }^{\circ} \mathrm{C}\right)\end{array}$ & $\begin{array}{c}\text { Model } \\
\left({ }^{\circ} \mathrm{C}\right)\end{array}$ & $\begin{array}{c}\text { Error } \\
(\%)\end{array}$ & $\begin{array}{c}\text { Measuring } \\
\left({ }^{\circ} \mathrm{C}\right)\end{array}$ & $\begin{array}{c}\text { Model } \\
\left({ }^{\circ} \mathrm{C}\right)\end{array}$ & $\begin{array}{c}\text { Error } \\
(\%)\end{array}$ & $\begin{array}{c}\text { Measuring } \\
\left({ }^{\circ} \mathrm{C}\right)\end{array}$ & $\begin{array}{l}\text { Model } \\
\left({ }^{\circ} \mathrm{C}\right)\end{array}$ & $\begin{array}{c}\text { Error } \\
(\%)\end{array}$ \\
\hline-0.3 & 4.43 & 4.5 & 1.6 & 4,31 & 4.45 & 3.2 & 4.3 & 4.45 & 3.5 \\
\hline-2 & 4.36 & 4.4 & 0.9 & 4.23 & 4.35 & 2.8 & 4.3 & 4.35 & 1.2 \\
\hline-4 & 4.33 & 4.35 & 0.5 & 4.2 & 4.29 & 2.1 & 4.3 & 4.24 & 1.4 \\
\hline-6 & 4.32 & 4.29 & 0.7 & 4.15 & 4.14 & 0.2 & 4.2 & 4.19 & 0.2 \\
\hline-8 & - & - & - & 4.16 & 4.08 & 1.9 & 4.1 & 4.03 & 1.7 \\
\hline-10 & - & - & - & 4.14 & 3.93 & 5.1 & 4.1 & 3.93 & 4.1 \\
\hline-12 & - & - & - & 4.17 & 3.87 & 7.2 & 4.1 & 3.87 & 5.6 \\
\hline-15 & - & - & - & 3.98 & 3.82 & 4.0 & 4 & 3.77 & 5.8 \\
\hline-20 & - & - & - & 3.8 & 3.61 & 5.0 & 4 & 3.61 & 9.8 \\
\hline-25 & - & - & - & 3.65 & 3.56 & 2.5 & 3.8 & 3.56 & 6.3 \\
\hline-30 & - & - & - & - & - & - & 3.8 & 3.56 & 6.3 \\
\hline-35 & - & - & - & - & - & - & 3.7 & 3.51 & 5.1 \\
\hline-40 & - & - & - & - & - & - & 3.6 & 3.45 & 4.2 \\
\hline-45 & - & - & - & - & - & - & - & - & - \\
\hline-50 & - & - & - & - & - & - & - & - & - \\
\hline-55 & - & - & - & - & - & - & - & - & - \\
\hline-59.8 & - & - & - & - & - & - & - & - & - \\
\hline an Err & entage: & & 0.9 & & & 3.4 & & & 3.8 \\
\hline
\end{tabular}

